\title{
Nondestructive Testing of 105mm Depleted Uranium Penetrators
}

\author{
C. J. Morris \\ S. J. Foreman
}

December 1979

Prepared for U.S. Army Armament Research and Development Command Dover, New Jersey

Pacific Northwest Laboratory Operated for the U.S. Department of Energy by Battelle Memorial Institute 


\title{
NOTICE
}

This repont was prepared as an account of work sponsored by the United States Government. Neither the United States nor the Department of Energy, nor any of their employees, nor any of their contractors, subcontractors, or their employees, makes any warranty, express or implied, or assumes any legal liability or responsibility for the accuracy. completeness or usefulness of any information, apparatus, product or process disclosed, or represents that its use would not infringe privalely owned rights.

The views, opinions and conclusions contained in this report ate those of the contractor and do not necessarily represent those of the United States Government or the United States Department of Energy.

\author{
PACIFIC NORTHWEST LABORATORY \\ operated by \\ BATTELLE \\ for the \\ UNITED STATES DEPARTMENT OF ENERGY \\ Under Contract EY-76-C-06-1830
}

\begin{tabular}{|c|c|c|}
\hline \multicolumn{3}{|c|}{$\begin{array}{l}\text { Peinted in the United States af Ametica } \\
\text { Avaliable from } \\
\text { National Technical Information Service } \\
\text { United States Department of Commerce } \\
5285 \text { Port Royal Road } \\
\text { Springtield, Virginia } 22151\end{array}$} \\
\hline Price: & Printed Copy 5 & $\because$ Microfiche $\$ 3.00$ \\
\hline & "Pages & $\begin{array}{l}\text { NTIS } \\
\text { Selling Price }\end{array}$ \\
\hline & $001-025$ & 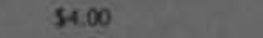 \\
\hline & $026-052$ & 54.50 \\
\hline & $051-075$ & 35.25 \\
\hline & $076-100$ & 56.00 \\
\hline & $107-125$ & 36.50 \\
\hline & 126.150 & 57.25 \\
\hline & $151-175$ & $\$ 800$ \\
\hline & $176-200$ & $\$ 9.00$ \\
\hline & 201.225 & 3925 \\
\hline & $226-250$ & 5950 \\
\hline & 251.275 & 510.75 \\
\hline & 276.300 & 517.00 \\
\hline
\end{tabular}


NONDESTRUCTIVE TESTING OF

$105 \mathrm{~mm}$ DEPLETED URANIUM

PENETRATORS

C. J. Morris

S. J. Foreman

December 1979

Prepared for

the U.S. Army Armament Research

and Development Command

Dover, New Jersey

under a Related Services Agreement with

the U.S. Department of Energy under

Contract EY-76-C-06-1830

Pacific Northwest Laboratory

Richland, Washington 99352 
SUMMARY

This report updates nondestructive testing activities for XM774 depleted uranium cores at PNL through November 1979. This has been a particularly active period for nondestructive testing with several organizations deserving recognition for their efforts.

The increase in inspection requirements for the XM774 Verification Program required expeditions development and performance testing of ultrasonic and eddy-current systems. Three ultrasonic inspection systems had to be developed to meet the program needs. As of this writing, one system is in operation at Nuclear Metals, Concord, MA. A second system is in operation at National Lead and a third under construction at PNL in support of the ultrasonic inspection efforts during this period was Mr. Merlin Micheal and staff at Rocky Flats Plant.

While ultrasonic testing activities were being pursued, Reluxtrol Company was designing and engineering a prototype eddy-current inspection system for the surface inspection requirements of the XM774. As a result of several successful demonstration tests a final semi-automated inspection system was delivered to Chamberlain Manufacturing in October 1979. A second duplicate system will be delivered to PNL In February 1980.

During this period many ARRADCOM personnel (N. Gravenstede, R. Sayer, J. Stack...) assisted and supported PNL's efforts in the installation and transfer of XM774 ultransonic test systems. In addition, ARRADCOM has helped in corrdinating several demonstration tests; worked on establishing specifications for an automated ultrasonic inspection system for production testing; developed depleted uranium eddy-current standards; worked on the development of ultrasonic depleted uranium standards; reviewed and evaluated ultrasonic and eddy-current data, and, initiated funding for fracture mechanics studies.

Our future efforts at PNL will entail testing of XM-774, -833 and -829 cores using ultrasonic and eddy-current inspection methods. U1trasonic attenuation measurements will be performed in January. Specimens will be fabricated for this test (flat-surface). 


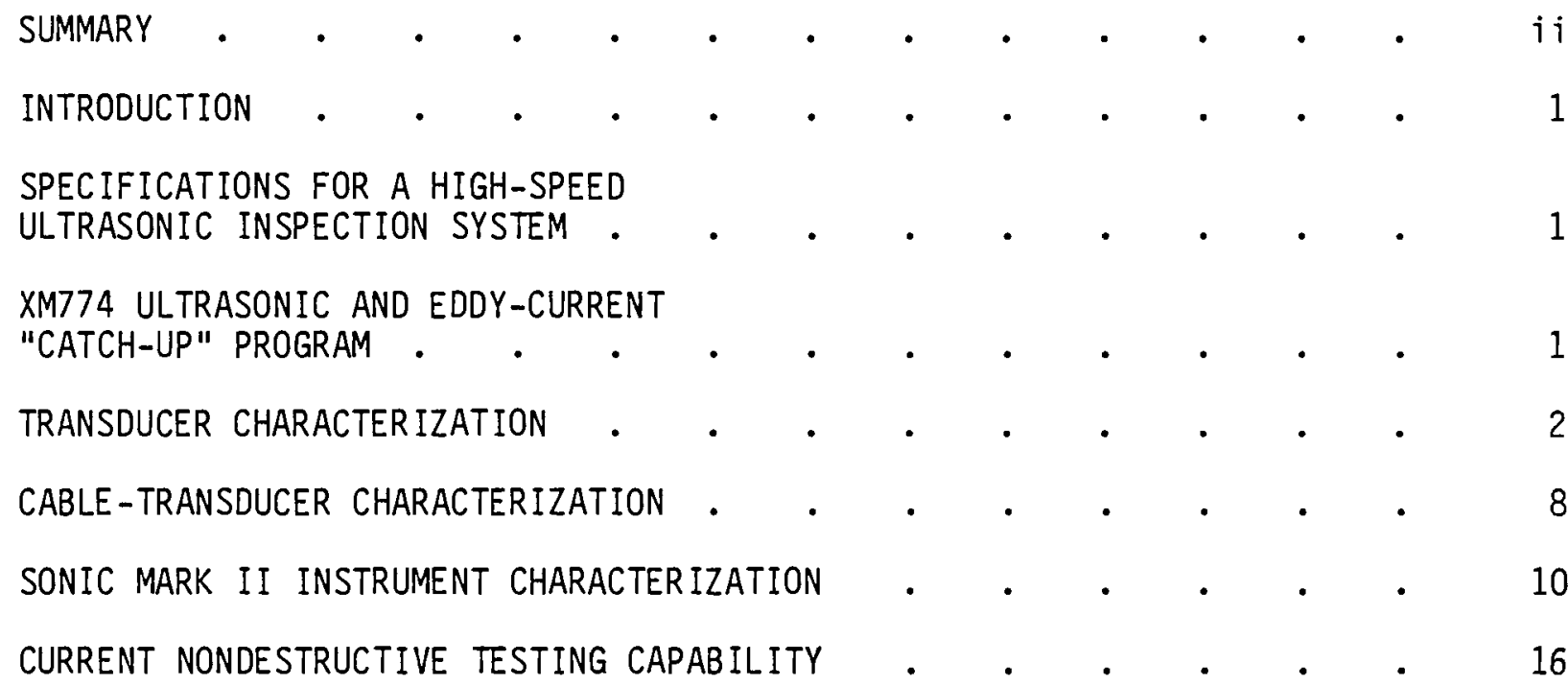

APPENDIX A: PNL REVIEW OF DRAFT SPECIFICATIONS FOR AN AUTOMATED

ULTRASONIC PRODUCTION TESTING SYSTEM • • • • • • A-1

APPENDIX B: GLOSSARY OF TERMS USED TO EVALUATE ULTRASONIC

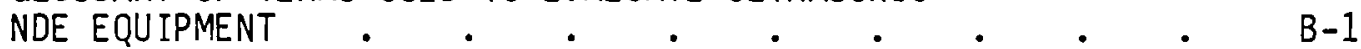

APPENDIX C: TRANSDUCER CHARACTERIZATION TEST PROCEDURE $\quad$ - . . $\quad$ C-1

$\begin{array}{ll}\text { APPENDIX D: } & \text { TRANSDUCER IMPEDANCE PLOTS AND TONE BURST } \\ & \text { SPECTRUM DATA }\end{array}$

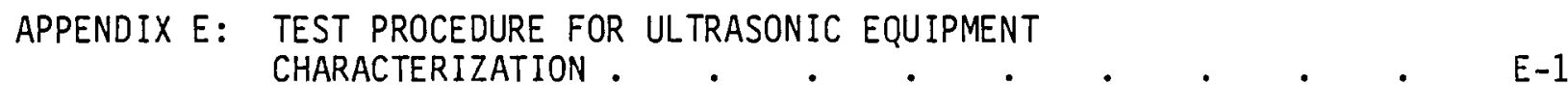




\section{FIGURES}

1. Impedance Plots Using Polar and Rectangular

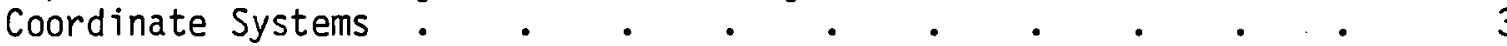

2. Complex Impedance Plots for Aerotech Transducer G19617 • • . 5

3. Tone Burst Spectral Response for Aerotech Transducer G19617 •

4. Signal Distortion Measured at Point $C$ for Various Cable Lengths . $\quad . \quad . \quad . \quad . \quad . \quad . \quad . \quad . .9$

5. Mark II Pulser Characterization Measurements

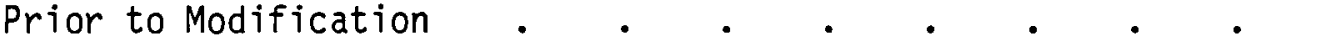

6. Mark II Pulser Characterization Measurements

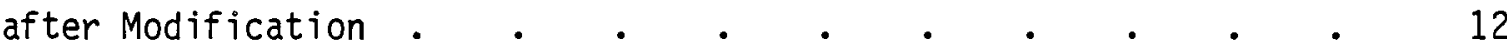

7. Block Diagram of the Sonic Mark II . . . . . . . . 13

8. Sonic Mark II Instrument Characterization Measurements for Minimum and Maximum Damping Control . . . . . . . 14

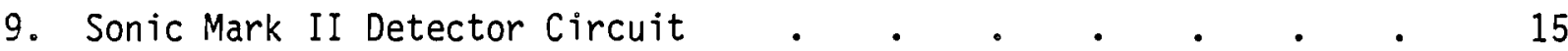

10. Simulated U1trasonic Instrument Detector Response Curves . . 15

11. Ultrasonic Pulse-Echo Response from Depleted Uranium Core no. 53 (fab. at Sandia Labs). . . . . . . . 18

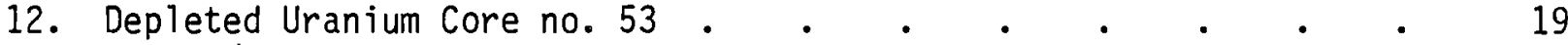

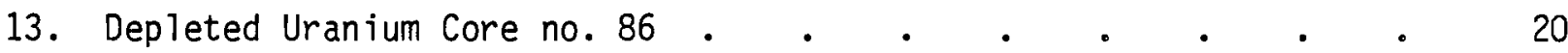

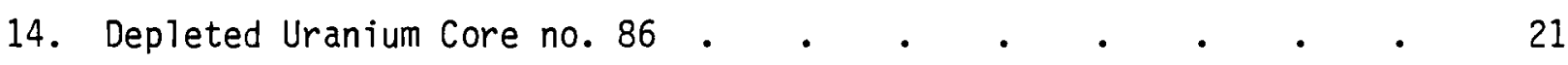

15. Depleted Uranium Core no. 86 . $\quad$ • . . . . 22

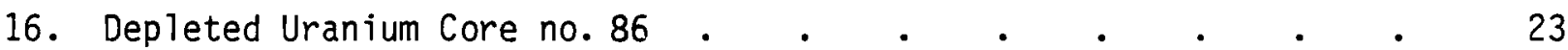

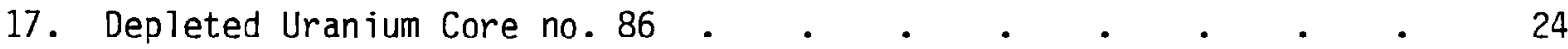

18. Depleted Uranium Core no. 86 .

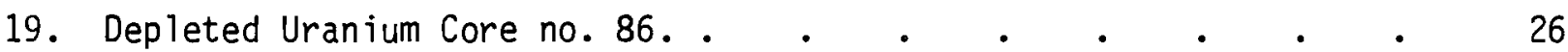

20. U1trasonic Inspection Results Core no. 212 


\section{FIGURES (contd)}

21. Core no. 212 (casting defect) as Received . . . . . . 29

22. Core no. 212 (casting defect), Centerline Section (defect length 3 in.). . . . . . . . . . 30

23. U1trasonic Inspection Results for Core no. 187

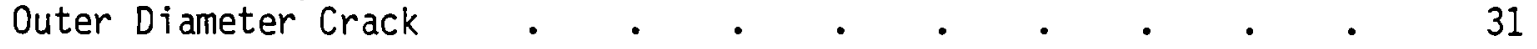

24. Core 187 O.D. Crack, Specimen Approximately 4 in. Length . . 32

25. U1trasonic Inspection Results for Core no. 621-1 with an Embedded Crack Approximately 6 in. Length . . . . . 34

26. Core no. 169 with Extrusion Defect; Centerline Section View; Specimen Length 2 in. 


\section{TABLES}

1. Summary of Transducer Data Using Tone Burst Method $\quad$ - $\quad$ - 7

2. Eddy Current Calibration Standard No. BNW47B $\quad$ - $\quad$ - 17 


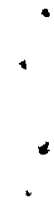


NONDESTRUCTIVE TESTING OF 105MM

DEPLETED URANIUM PENETRATORS

INTRODUCTION

This report is an information update concerning the nondestructive testing (NDT) activities at Pacific Northwest Laboratories (PNL) for depleted uranium penetrator (XM774, XM833) quality inspection and evaluation. This report covers NDT activities from August to November, 1979.

SPECIFICATIONS FOR A HIGH-SPEED ULTRASONIC INSPECTION SYSTEM

$\mathrm{Mr}$. R. Sayer (a) has requested comments concerning the preliminary specifications for an automated ultrasonic inspection system for the XM774 penetrators. PNL comments on the draft specification are included in a letter to Mr. J. Stack in Appendix $A$. This report provides additional technical data that can be used in developing ultrasonic test system performance specifications (refer to sections on trasnducer and instrument characterization).

\section{XM774 ULTRASONIC AND EDDY-CURRENT "CATCH-UP" PROGRAM}

On August 24 I visited with Mr. Al Gilman (Quality Assurance Manager) of Nuclear Metals Inc. (NMI) to discuss the details of the new ultrasonic test system now in use at NMI. I spent some time giving $A 1$ and Mr. Dave Purinton (Level II Technician) an update of our present scope of activities at PNL and reviewed some of the nondestructive-destructive confirmatory research that has been performed over the past year.

As you are well aware the system was delivered to NMI the last week of September. Sid Foreman (PNL Senior NDT Technician) set up the system and ran several tests to determine operational capability. After the system was qualified, (using PNL supplied standards), Sid Foreman and Dave Purinton inspected approximately 50 penetrators.

Unfortunately the microprocessor-controlled Mark II electronic package was not ready at the time of the NMI delivery. Several electronic problems surfaced during the first trial test of this prototype system. However, it now appears that system debugging has eliminated several problem areas and in the future this electronic instrument will be delivered to NMI. The microprocessor enables one to use a single Mark II pulser to drive 4 transducers by multiplexing methods. The system was designed so that each test, whether it be a $45^{\circ}$ shear examination or a pulse-echo examination, can be individually selected for system calibration and flaw-amplitude gate positioning. In addition, if the multiplexer failed during operation of the system the operator would always be able to manually select the desired test mode and proceed with the inspection tasks.

(a) Letter from Mr. R. Nelson (Rocky Flats) of October 5, 1979. 
During this trip Sid Foreman also visited Battelle Columbus Laboratories and National Lead Company of Ohio to deliver ultrasonic test standards and provide instruction as to current test procedures.

PNL is currently working on a third ultrasonic inspection system that will be completed by December 25, 1979. This system will be similar to the system at Nuclear Metals.

During the months of August through November a prototype eddy-current system was designed, developed, engineered and tested for inspection of finished XM774 cores. Three demonstration tests were conducted during this period at PNL, Reluxtrol, and Chamberlain Manufacturing Company. These demonstration tests were very successful and enabled Reluxtrol to deliver a semi-automated eddy-current inspection system to Chamberlain in late October 1979.

Recently, C. Morris attended a demonstration test at IRT Corporation (San Diego) to witness gamma-scan inspection of depleted uranium cores. The results of this demonstration test were reviewed by PNL and a letter report was sent to $\mathrm{Mr}$. R. Sayer and Mr. N. Gravenstede of ARRADCOM.

\section{TRANSDUCER CHARACTER IZATION}

In order to verify Mark II multiplexer operation measurements were made to determine the pulser acoustic frequency spectrum before the instrument was modified and after modification. Specifically two measurements were made to assess instrument performance. The pulser frequency spectrum was measured using a 50 ohm load termination as a baseline reference. The pulser was designed to see a $50 \mathrm{ohm}$ resistive load. Knowing this one should achieve optimum pulser performance when driving this load. On the other hand, a transducer presents a complex electronic impedance, $(Z)$, comprised of a real resistive component, $(R)$, and an imaginary reactive component $(j X)$ that is frequency dependent. The reactive terms being the reactive inductance ( $\left.j X_{c}\right)$ and capacitance $(-j \times c)$. Transducer impedance is defined as:

$$
Z_{T}=R+j\left(X_{L}-X_{C}\right)
$$

or as a phasor:

$$
z_{T}=z \angle e
$$

Figure 1 shows an example of impedance plots using polar and rectangular coordinates.

Several of the focused ultrasonic transducers used in the NDT XM774 program were measured to determine key performance parameters (test procedure described in Appendix C). The technique used to evaluate the transducers utilizes a narrow band or tone burst $(a)$ excitation (see Appendix $D$ data) swept over the frequency band of interest ( 1 to $10 \mathrm{MHz}$ ). The resultant technique provides engineering data on the electrical parameters and acoustic performance of the transducer and affords a highly reliable and reproducible method of evaluating transducers. In short, the technique evaluates the transducer as though it 


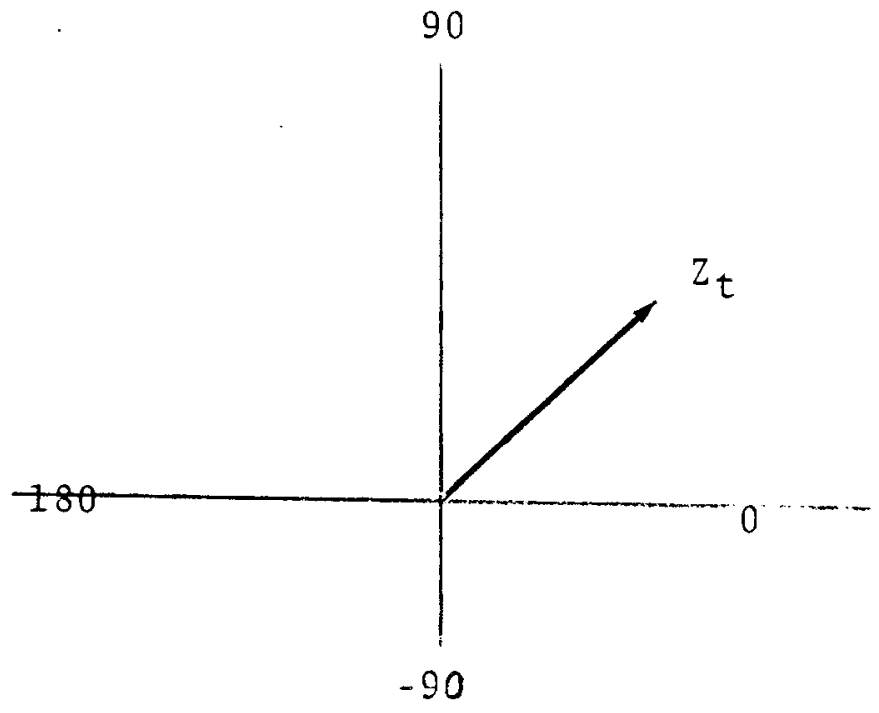

(a) Polar Co-ordinates

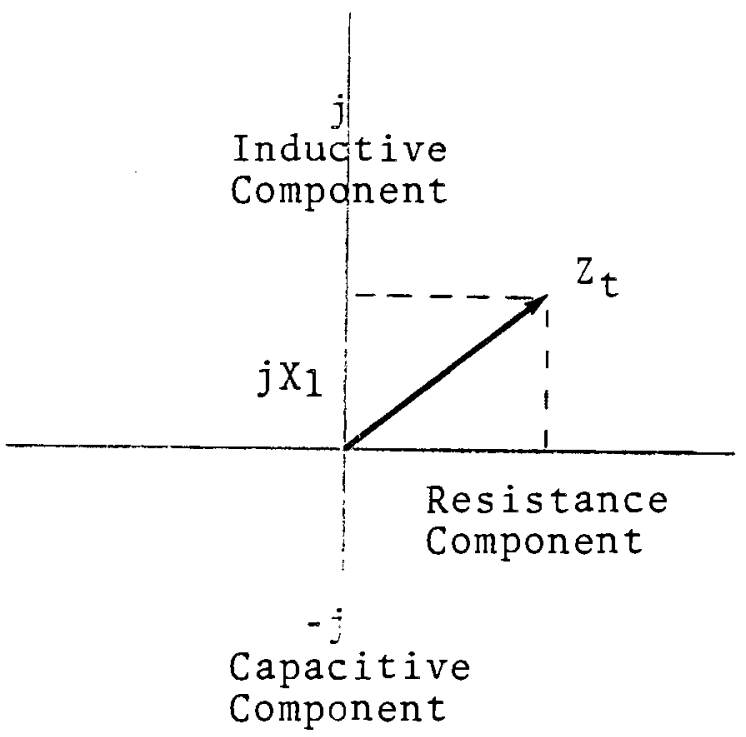

(b) Rectangular Co-ordinates

FIGURE 1. Impedance Plots Using Polar and Rectangular Coordinate Systems

were a discrete element, separate from other influences and variables such as the coaxial cable or excitation signals of uncontrolled frequency content.

Transducer characterization parameters of interest are:

1. Complex impedance and phase angle measurement - The impedance value and resultant phase angle determines how effectively the pulse energy will be absorbed by the transducer or "load." Defective or out of tolerance construction can be determined with this test.

2. Peak frequency - The peak frequency test determines the frequency at which the transducer response across a known frequency band is maximized.

This test will determine if the transducer is operating off of its nominal frequency and provides data to determine its actual bandwidth. These parameters are of importance to predict the resolution capabilities of the transducer and its suitability for certain pattern recognition/signal analys is techniques.

3. Bandwidth - Bandwidth is a parameter that results from the broadness of frequency response in the pulse echo mode and is the difference between the $6 \mathrm{~dB}$ points above and below the peak frequency determined earlier. Measurements are obtained from the spectrum plots for each transducer.

(a) Erikson, K. R., "Tone Burst Testing of Pulse Echo Transducers." 
4. Insertion loss - Insertion loss provides a relative measure of sensitivity of a transducer. This figure is an excellent guide for selecting transducer sensitivity for various applications.

5. "Q" of the transducer - This is a term used to evaluate the damping of the transducer's acoustic response. It is also an indicator of the sharpness of tuning at the peak operating frequency.

An example of the collected data showing the complex impedance plot and the tone burst spectral response plot, are shown in Figures 2 and 3 respectively. Figure 2 shows that the peak frequency response is in excess of $10 \%$ of the nominal frequency (name plate $5.0 \mathrm{MHz}$ ) using tone burst excitation for Aerotech transducer ( $G$ 19617, Pb MET, $5.0 \mathrm{MHz}, 0.5$ in. diameter, medium damped). Figure 3 shows the impedance plot for the untuned Aerotech transducer, the impedance plot of the transducer with a $0.752 \mu \mathrm{H}$ inductor in parallel with the element, and, the optimum impedance (50 ohm $\pm 10 \%$ at a phase of +300 and -100 ) obtained by tuning the transducer with a $0.752 \mu \mathrm{H}$ inductor and $75 \mathrm{ohm}$ resistor in parallel with the element. Table 1 shows a summary of transducer characterization data.

Tests were conducted using this particular Aerotech transducer to demonstrate the improved performance achieved by correcting the impedance of the transducer or "tuning" the transducer to obtain a $50 \mathrm{ohm}$ resistive load $\left(0^{\circ}\right.$ phase angle). From the impedance chart it was observed that the untuned impedance varied in magnitude from 10 ohms at $10.0 \mathrm{MHz}$ to 104 ohms at $1.5 \mathrm{MHz}$ at a constant phase angle of $-88^{\circ}$. These measurements were made using a sine-wave excitation swept from $1 \mathrm{MHz}$ to $10 \mathrm{MHz}$ using a vector impedance meter. The results of this experiment were:

- Tuning the transducer by the addition of a complimentary inductor and appropriate shunt resistor adjusted the impedance value and phase angle to a desirable range, as shown in the impedance plots.

- The insertion loss with the addition of tuning elements was reduced by over $3 \mathrm{~dB}$ with a slight bandwidth narrowing. With proper impedance and phase angle the transducer operated in a very predictable manner independent of damping control setting and cable type or length.

The need for agreement of nominal and actual operating frequencies within set tolerances that permit reproducible test results is self-evident. The most important reason for controlling transducer impedance values is to properly dissipate energy at the transducer and thereby minimize reflections which result in signal distortion and increased noise. It has long been recognized in ultrasonic testing that of ten there is a lack of concern, and subsequently no control of, transducer performance. Transducers are selected to meet minimum "catalog" specifications. PNL tests have shown that by specifying key parameters such as:

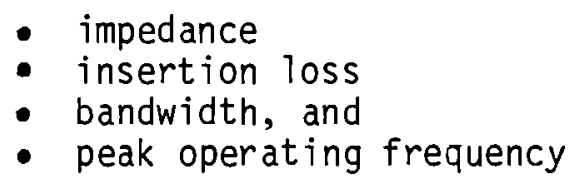




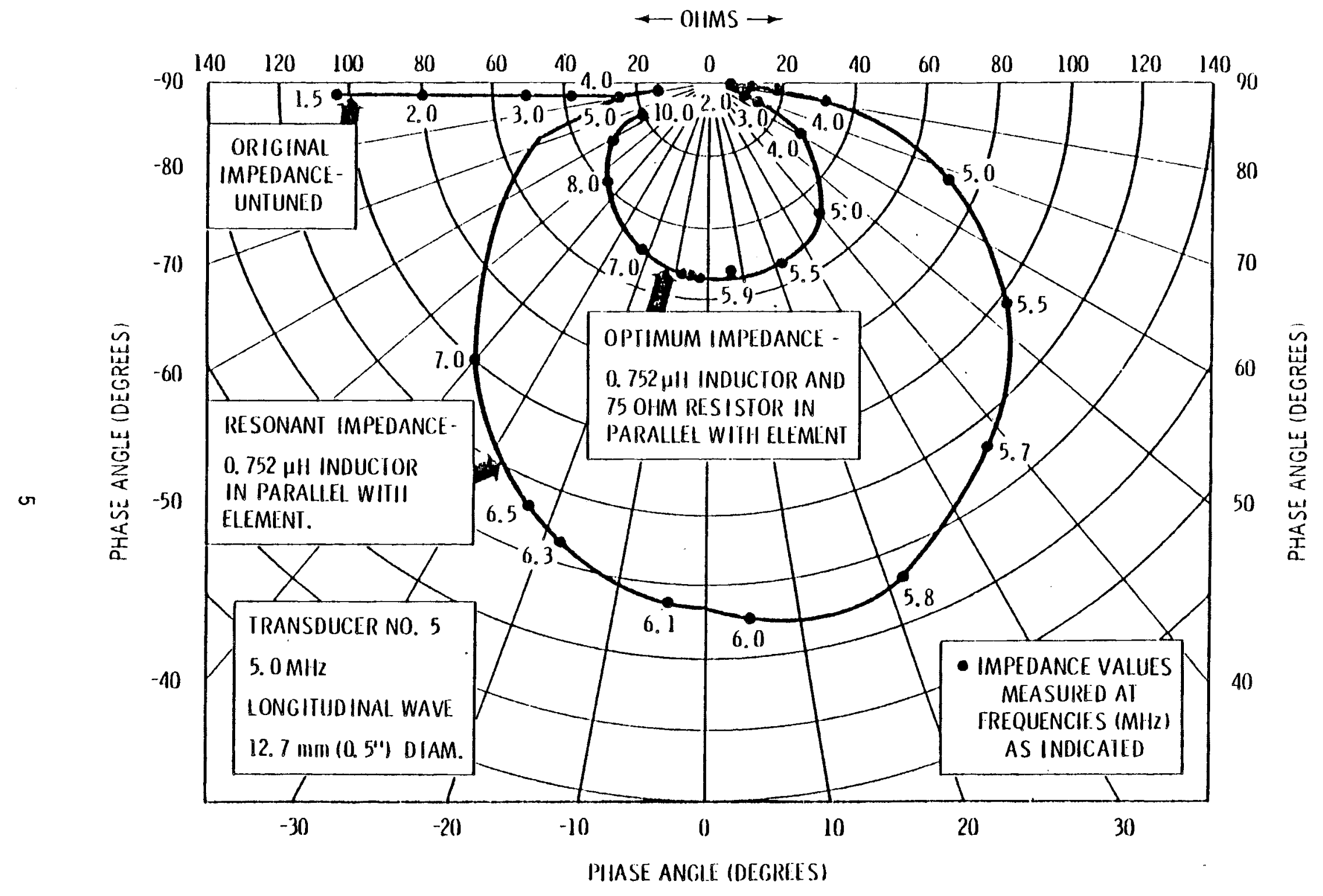

FIGURE 2. Complex Impedance Plots for Aerotech Transducer G19617 


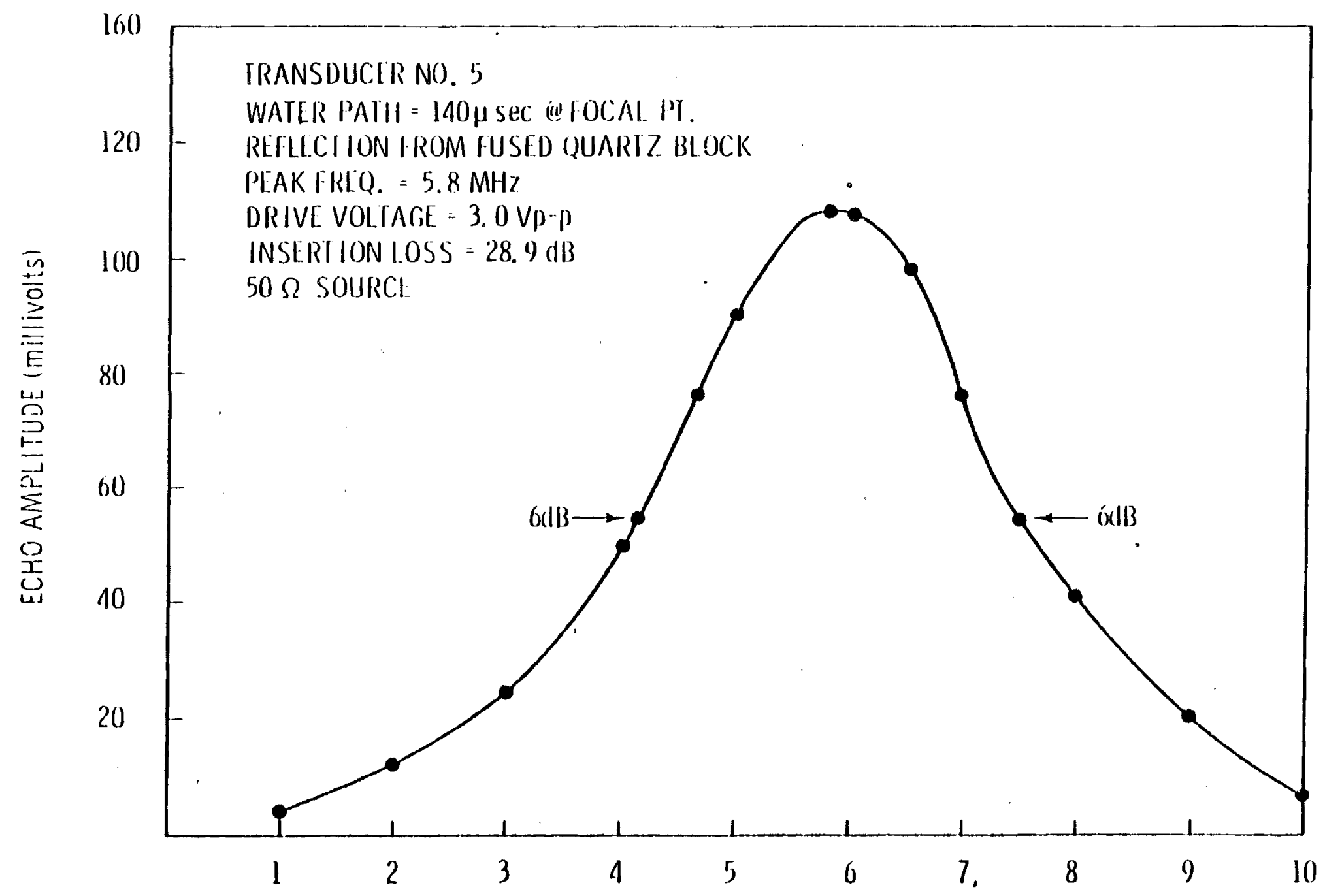

FREQUENCY (MHZ)

FIGURE 3. Tone Burst Spectral Response for Aerotech Transducer G19617 
TABLE 1. Summary of Transducer Data Using Tone Burst Method(c)

\begin{tabular}{|c|c|c|c|c|c|}
\hline Number & $\begin{array}{c}\text { Electrical } \\
\text { Tuning } \\
\end{array}$ & $\begin{array}{l}\text { Crystal } \\
\text { Material }\end{array}$ & $\begin{array}{l}\text { Nominal } \\
\text { Freq., } \mathrm{MHz}\end{array}$ & $\begin{array}{c}\text { Focal } \\
\text { Length }\end{array}$ & Size \\
\hline $\begin{array}{l}\text { Harr ison ic } \\
(\mathrm{Q} 2 / 20)\end{array}$ & Yes & $\mathrm{Pb} \mathrm{MET}_{\mathrm{K} 83}$ & 5 & $152.4 \mathrm{~mm}$ (6 in.) & $19.0 \mathrm{~mm}(0.75 \mathrm{in.})$ \\
\hline $\begin{array}{l}\text { Aerotech } \\
\text { ( G 19617) }\end{array}$ & No & $\mathrm{Pb}$ MET & 5 & $101.6 \mathrm{~mm}$ (4 in.) & $12.7 \mathrm{~mm}$ (0.5 in.) \\
\hline $\begin{array}{l}\text { Harrisonic } \\
\text { (R571) }\end{array}$ & Yes & $\mathrm{Pb} \mathrm{MET}_{\mathrm{K} 83}$ & 10 & $76.2 \mathrm{~mm}$ (3 in.) & $12.7 \mathrm{~mm}(0.375 \mathrm{in.})$ \\
\hline $\operatorname{PAD}(B N 5-02)$ & XFORMER & $\mathrm{PZT}$ & 5 & $101.6 \mathrm{~mm}$ (4 in.) & $12.7 \mathrm{~mm}$ (0.50 in.) \\
\hline
\end{tabular}

\begin{tabular}{|c|c|c|c|c|c|c|}
\hline \multirow{2}{*}{$\begin{array}{l}\frac{\text { Number }}{\text { Harrisonic ic }} \\
\text { (Q2120) }\end{array}$} & \multirow{2}{*}{$\begin{array}{l}\text { Peak (b) } \\
\text { Freq., MHz } \\
5.05\end{array}$} & \multirow{2}{*}{$\begin{array}{c}\begin{array}{c}\text { Insertion } \\
\text { Loss } d B\end{array} \\
-44\end{array}$} & \multirow{2}{*}{$\begin{array}{l}\text { Bandwidth } \\
(-6 \mathrm{~dB}), \mathrm{MHz} \\
4.55\end{array}$} & \multirow{2}{*}{$\frac{Q}{1.1}$} & \multicolumn{2}{|c|}{$\begin{array}{c}\text { Complex } \\
\text { Impedance } \\
\text { a Peak } \\
\text { Freq., ohms }\end{array}$} \\
\hline & & & & & 48 & $-26^{0}$ \\
\hline $\begin{array}{l}\text { Aerotech } \\
\text { (G 19617) }\end{array}$ & 5.8 & -28.9 & 3.35 & 1.7 & 25 & $-88^{0}$ \\
\hline $\begin{array}{l}\text { Harrisonic } \\
\text { (R571) }\end{array}$ & 11.4 & -19.2 & 7.95 & 1.4 & $36^{\circ}$ & $+26^{\circ}$ \\
\hline $\operatorname{PAD}(B N 5-02)$ & 4.9 & -8.0 & 2.0 & 2.5 & 5.0 & $0^{0}$ \\
\hline
\end{tabular}

(a) For non-focused: set $Y_{0}=02 / 42$.

(b) All values established at transducer.

(c) Tone burst spectra and impe dance plots in Appendix D. 
one would require the supplier of these transducers to pay close attention to transducer fabrication, thus ensuring a quality product. The supplier would be told that measurements of key operating parameters (in water) will be performed according to a specific test procedure. Transducer acceptance will be governed by the operational test results. Reasonable tolerances would be placed on the operating parameters such that the buyer does not incure unnecessary or unreasonable costs for manufacture of the transducers.

\section{CABLE-TRANSDUCER CHARACTERIZATION}

Tests conducted with the Aerotech transducer and a Harrisonic transducer Table 1 representing unacceptable (25 ohms) and acceptable (48 ohms) impedance values respectively, demonstrate that correctly terminated (48 ohms) coaxial cables of various lengths provide little signal distortion versus incorrectly terminated (25 ohms) cables which exhibited significant signal modification. Results are shown in Figure 4.

It is instructive to show that adjustment of the damping control to maximum, gives different results in comparison to the minimum damping setting using the same Aerotech transducer. Compare the results in column $1 c$ of Figure 8 . The reader will note that the pulse is now more broad banded, with a peak frequency at $5.0 \mathrm{MHz}$ (shifted up $1.5 \mathrm{MHz}$ ) compared to the $3.4 \mathrm{MHz}$ narrow band signal results at the minimum damping setting.

Point $B, C, D$ and $E$ data for minimum damping control settings are discussed below. Detailed test procedures and measurement equipment is included in Appendix E. The Aerotech (G19617) transducer was used to make Point B-E measurements.

Point $B$ data shows the transmitted acoustic wave. Measurements are made by pulsing the test transducer into a broadband $25 \mathrm{MHz}, 0.5$ inch diameter, lithium sulfate transducer. The r.f. waveform shows that there is a broadening of the transmitted acoustic signal, with the frequency spectrum showing that this broadening effect occurs at the $-6 \mathrm{~dB}$ points and at the higher spectral frequencies. Signal broadening is due to the tendency of the transducer to oscillate at its natural resonant frequency of $5.8 \mathrm{MHz}$ (re: Figure 3 ). Peak frequency of the signal is $3.4 \mathrm{MHz}$ which remains constant for Point $\mathrm{C}$ through $E$ measurements.

Point $C$ shows the reflected acoustic signal produced by pulsing the test transducer onto a flat surface (i.e., quartz block). Note that there are two distinct peaks in the frequency spectrum. One being at $3.4 \mathrm{MHz}$ and the other at 6.1 $\mathrm{MHz}$. If we refer back to Figure 3, one can see that the "tone burst" response of the test transducer peaked at $5.8 \mathrm{MHz}$. What has happened here is that the transducer has responded (as it should) to the higher frequency components of the transmitted pulse. Note in Figure 3 that the transducer response at $3.4 \mathrm{MHz}$ is well below the $6 \mathrm{~dB}$ point. It is more sensitive to excitation frequencies around $5.8 \mathrm{MHz}$. 
TRANSDUCER \#3

$48 \mathrm{Ohm}$ Impedance

(a) $-26^{\circ}$
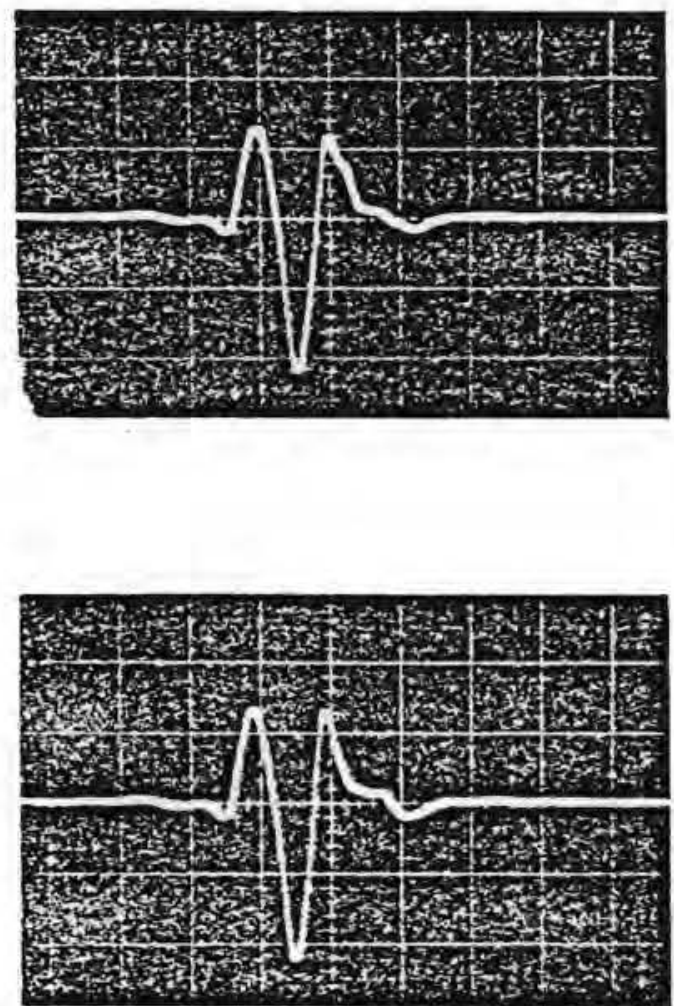

$1.85 \mathrm{~m}(6 \mathrm{ft}$.

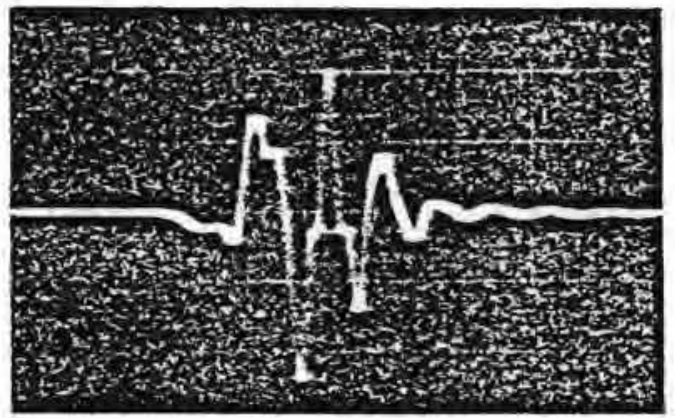

$3.04 \mathrm{~m}(10 \mathrm{ft}$.

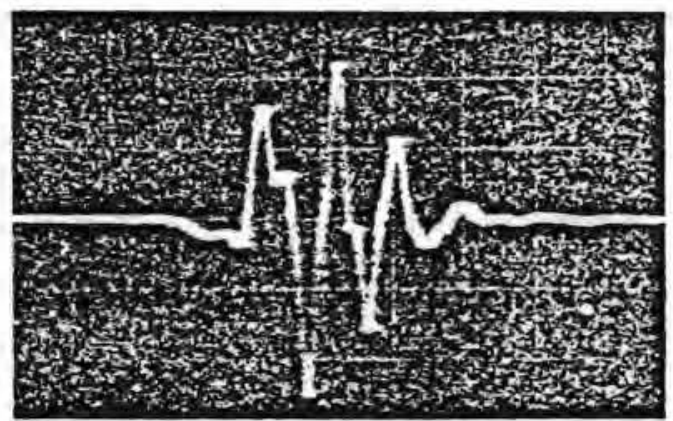

$4.57 \mathrm{~m}(15 \mathrm{ft}$.

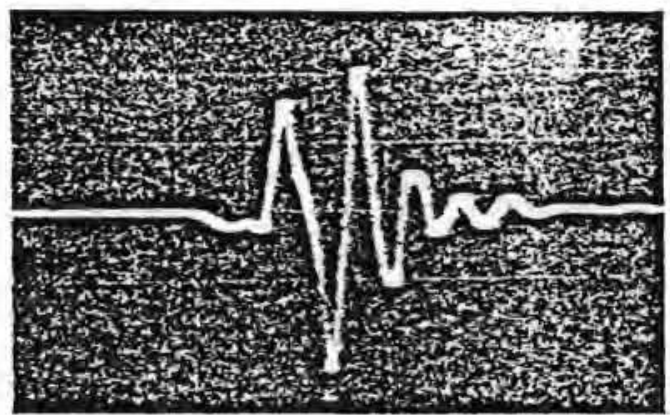

FIGURE 4. Signal Distortion Measured at Point $C$ for Various Cable Lengths 
Unlike the well controlled narrow band "tone burst" excitation used for transducer characterization measurements, most commercial ultrasonic flaw detection instruments use a "shock burst" excitation to produce an electrical pulse as shown in Figure 5b. Figure 5b shows the gated $r . f$. (radio frequency) shock burst pulse produced by the Sonic Mark II set at $5.0 \mathrm{MHz}$ operation (minimum damping) with a $50 \mathrm{ohm}$ load. The acoustic spectrum of this pulse is shown in Figure 5a. Note the peak frequency for a $50 \mathrm{ohm}$ load is $5.8 \mathrm{MHz}$ (i.e., $2 \mathrm{MHz}$ per division, center frequency (a $10 \mathrm{MHz}$ ). Figure $5 \mathrm{c}$ and $5 \mathrm{~d}$ show similar data, however, note the dramatic difference in the pulse shape and acoustic spectrum that results when the Aerotech ( $G 19617,5.0 \mathrm{MHz}$, nominal) transducer is connected to the Sonic Mark II instrument. The peak frequency response has now shifted to $3.4 \mathrm{MHz}$ with the pulse shape now very narrow banded. Therefore, for this particular transducer-pulser combination the operator of the inspection system would unknowingly think that one is inspecting at or near $5.0 \mathrm{MHz}$ when in fact penetrator inspection is being performed at $3.4 \mathrm{MHz} .1$

I was particularly interested in these measurements because of the microprocessor modification to the Mark II. It was important to ascertain data defining original equipment operation prior to modification. Figures $6 a$ and $6 \mathrm{~b}$ show the acoustic spectrum and $r . f$. waveform results when the Mark II is multiplexing and driving a 50 ohm load. Figures $6 \mathrm{c}$ and $6 \mathrm{~d}$ show the acoustic spectrum and $r . f$. waveform results when the Mark II is multiplexing and driving the Aerotech (G 19617) transducer at $5.0 \mathrm{MHz}$. These measurements show acoustic spectrum and $r . f$. waveform data that is identical to the measurement data taken prior to the modification. Therefore, I conclude that the system was not altered in any way that might hinder test performance.

Measurements were also taken of the r.f. waveform and acoustic spectrum at selected test performance points in the Sonic Mark II instrument (marked A through $E$ in the basic block diagram of Figure 7 ). Figure 8 shows the results of the measurements with the pulser/receiver control set to $5.0 \mathrm{MHz}$. Figure 8 shows data with the pulse damping control set for minimum and maximum damping. The damping. control is used to control pulse ringing (variable resistor: $50 \mathrm{ohm}$ to $2000 \mathrm{ohm}$ ) and enables tuning of the pulser/receiver and transducer system.

Previously, we discussed Point A measurement results. Specifically, Figures 5 and 6 showed test data (Aerotech, G $19617,5.0 \mathrm{MHz}$, nominal) to characterize Mark II performance prior to, and after, instrument modification. Data was presented showing the dramatic differences in performance that can result when transducers are randomly selected and not matched to instrument specifications. This results in signal distortion, loss of resolution, unwanted noise and uncertain operating frequency.

Point $D$ shows the amplified acoustic signal and is used to characterize signal amplification of the received signal from Point $C$. The data shows that the received acoustic signal was reproduced without distortion or any shift in frequency that could result from the receiver bandwidth being unacceptable. The $3 \mathrm{~dB}$ receiver bandwidth was measured to be from $2.2 \mathrm{MHz}$ to $11.5 \mathrm{MHz}$, or $9.3 \mathrm{MHz}$, which is exceptionally good for a commercial instrument. Our 


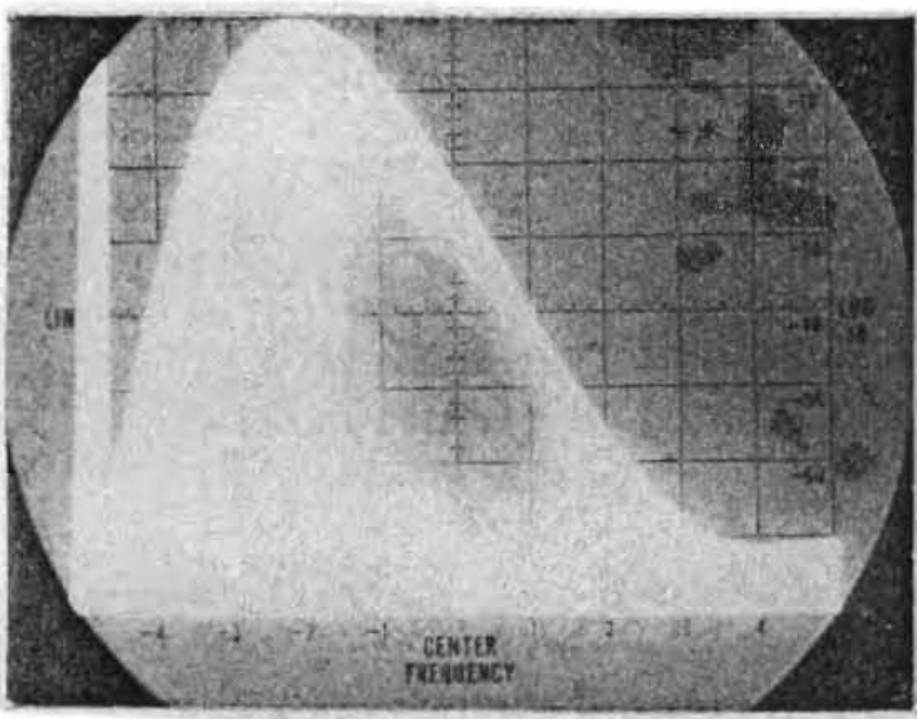

(a) $50 \Omega$ Load Frequency Spectrum

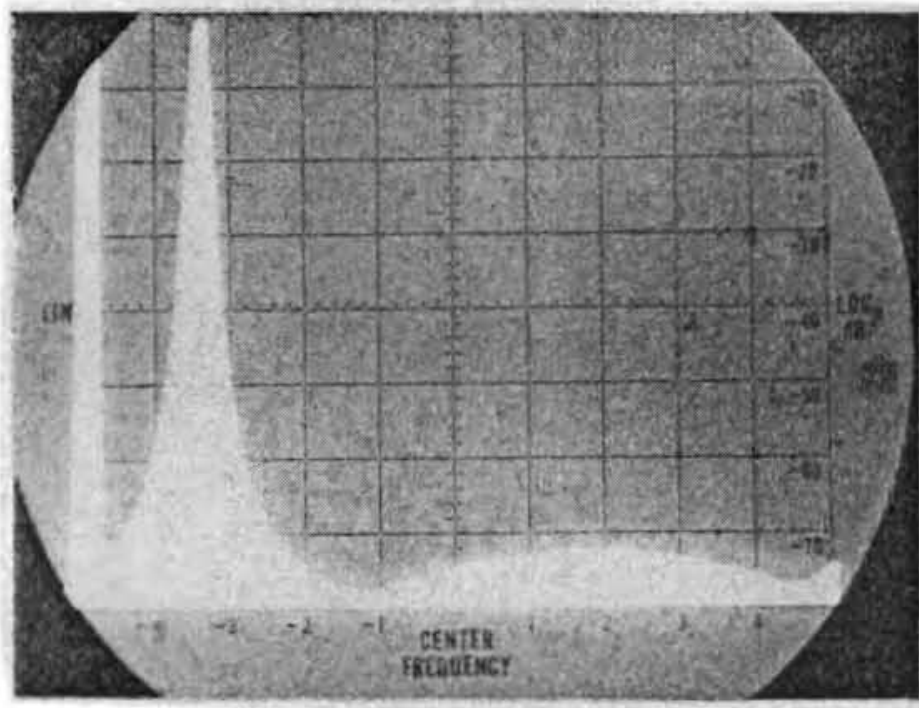

(c) AEROTECH (G 19617, $5.0 \mathrm{MHz}$ Nominal) Transducer Load Frequency Spectrum

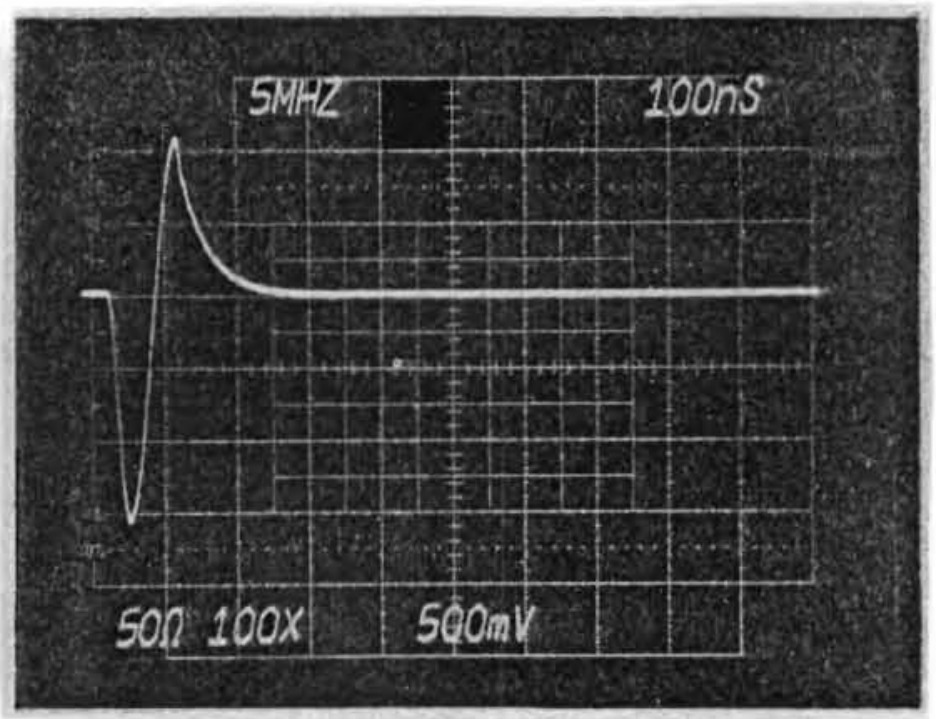

(b) Gated r.f. Waveform from $50 \Omega$ Load

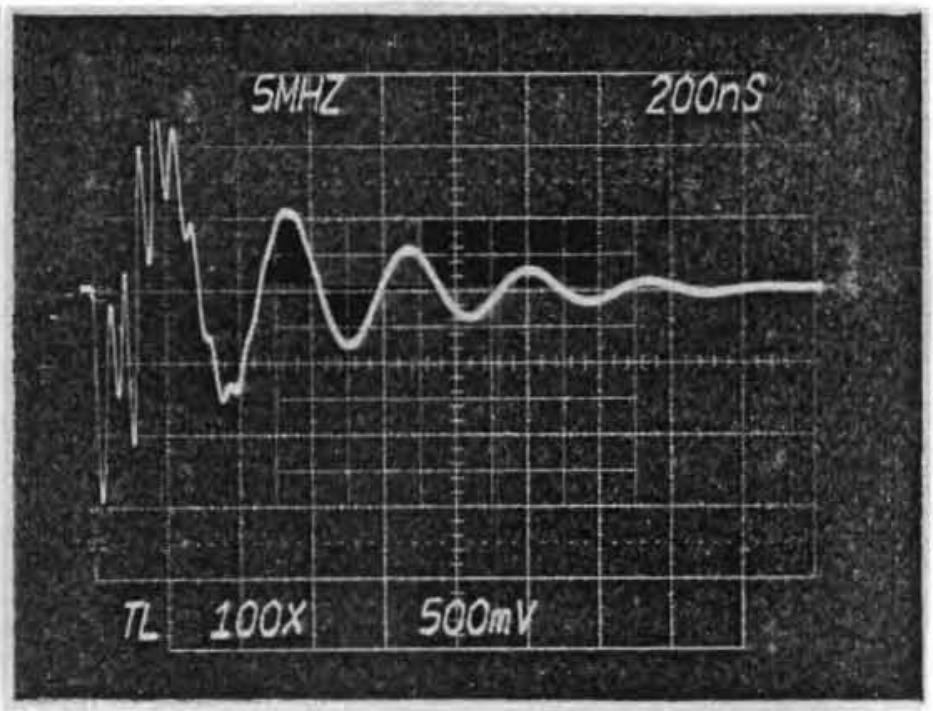

FIGURE 5. Mark II Pulser Characterization Measurements Prior to Modification. 


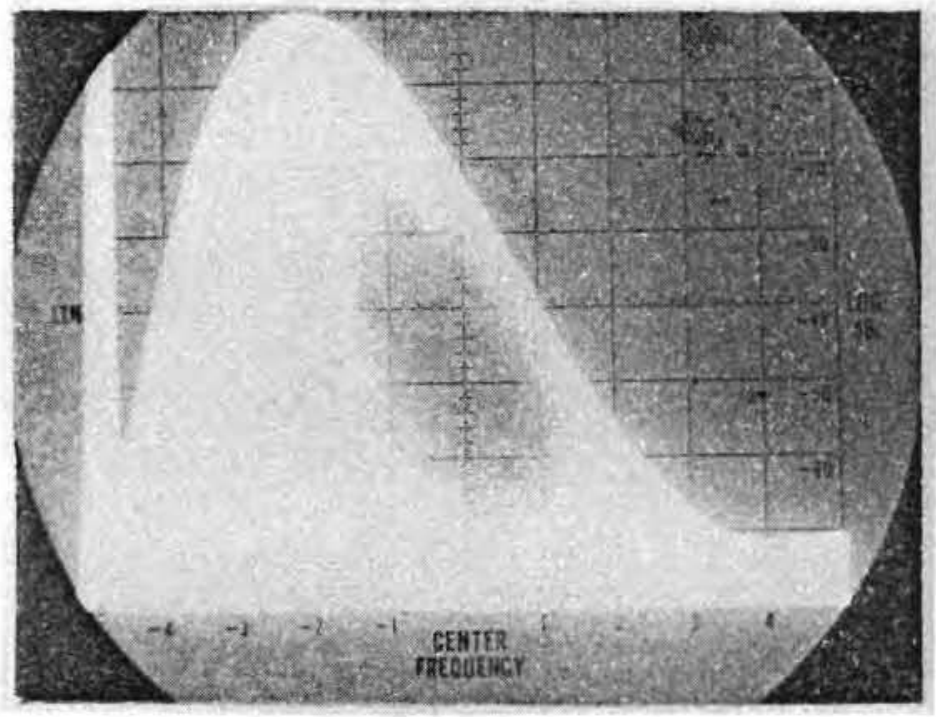

(a) $50 \Omega$ Load Frequency Spectrum

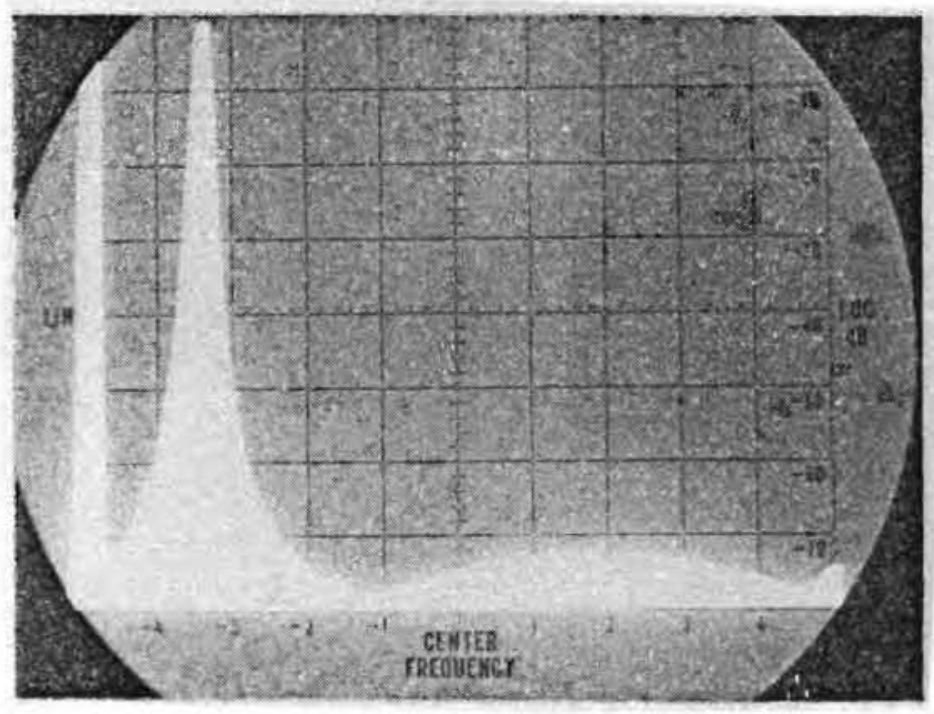

(c) AEROTECH (G 19617, $5.0 \mathrm{MHz}$ Nomina 1) Transducer Load Frequency Spectrum

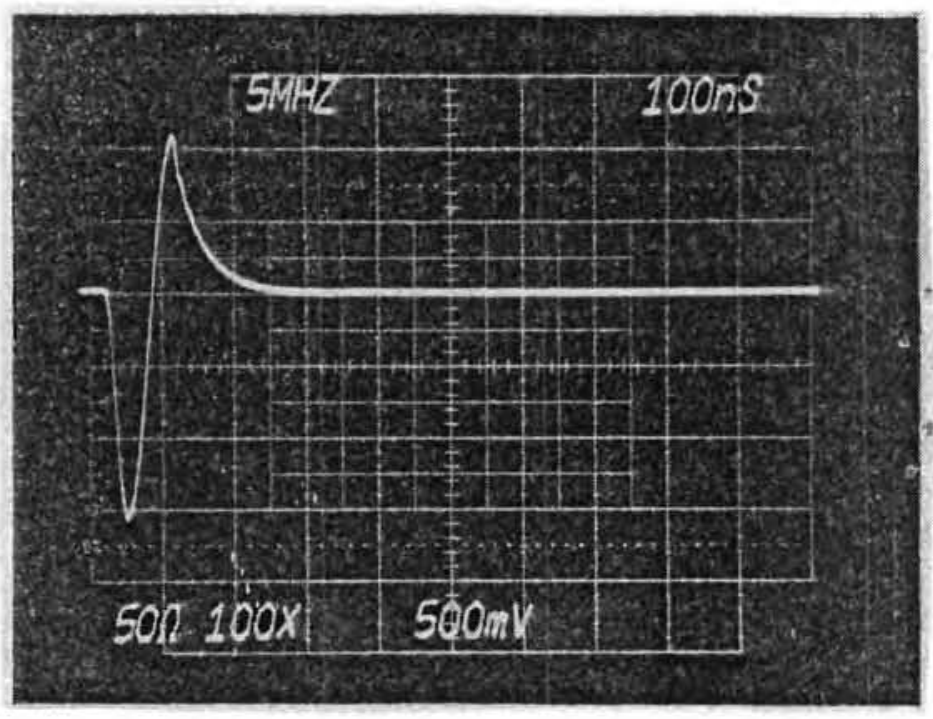

(b) Gated r.f. Waveform from $50 \Omega$ Load

FIGURE 6. Mark II Pulser Characterization Measurements after Modification

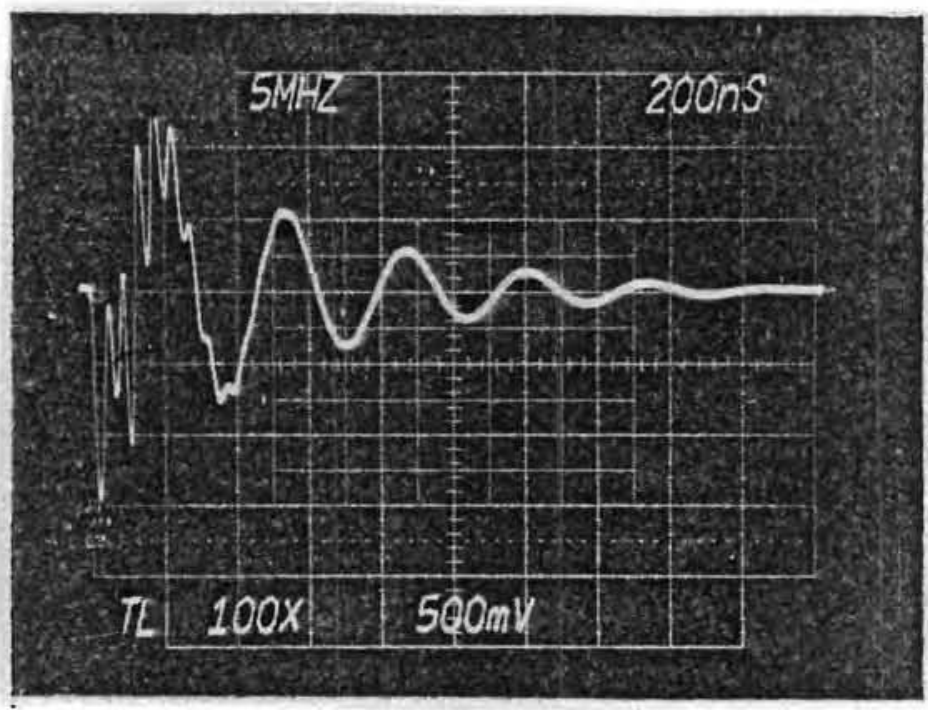

(d) Gated r.f. Waveform from AEROTECH Transducer 


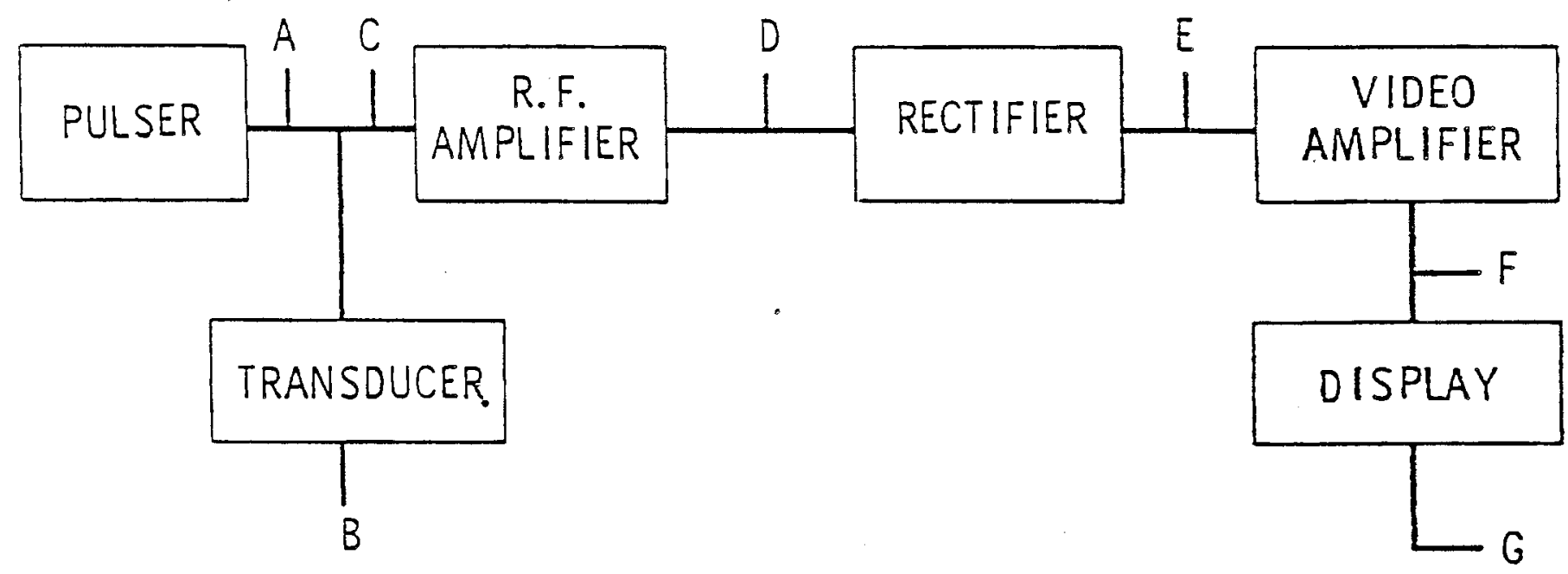

FIGURE 7. Block Diagram of the Sonic Mark II

pulse spectrum at Point $C$ shows that the input to the receiver (peak frequency $3.4 \mathrm{MHz}$ ) is at the lower end of the receiver bandpass, but within this bandpass. Other commercial instruments that were measured showed much more narrow band receivers. For example, the Automation 771 with the $10 \mathrm{~N}$ pulser/receiver module $3 \mathrm{~dB}$ receiver bandwidth from $3.9 \mathrm{MHz}$ to $5.7 \mathrm{MHz}$, or $1.80 \mathrm{MHz}$. If this same Point $C$ pulse were amplified by the $10 \mathrm{~N}$ the signal would likely be shifted in frequency and distorted once again (however the $10 \mathrm{~N}$ pulser/receiver was designed for narrow band operation). With this in mind one can consider the approach of going with a broadband pulser and receiver.

Point $E$ shows the detected or video drive signal of the amplified acoustic wave (Point $D$ ). The Mark II uses a full wave detector (some instruments use half wave detectors) at all tuned frequencies (i.e., $5.0 \mathrm{MHz}$, operation). A block diagram is shown in Figure 9.

The full wave detector takes the input signal and uses a phase splitter to shift the incoming acoustic signal $180^{\circ}$. Acoustic signals are then detected using transistors in the common emitter mode, clipped, and added to give a full wave signal which is filtered and feed to the video drive circuitry as shown in Figure 9.

I have not taken data at specific tuned receiver frequencies of $1.0 \mathrm{MHz}$, 2.0 MHz, 5.0 MHz, and $10.0 \mathrm{MHz}$. However, based upon previous measurement of detector response for commercial instruments it is likely that there may be some nonlinearity problems with the Mark II such that what you put in does not necessarily come out. Specifically what one would like to see is a linear response curve as shown in Figure 10 (solid line), where the equation for the line is $y=x$. However, it is possible that the operating curve is nonlinear and is exponential $\left(1-e^{-x}\right)$ as shown with the dashed line of Figure 10 . If the dashed line did represent the detector response of the Mark II at $5.0 \mathrm{MHz}$, 


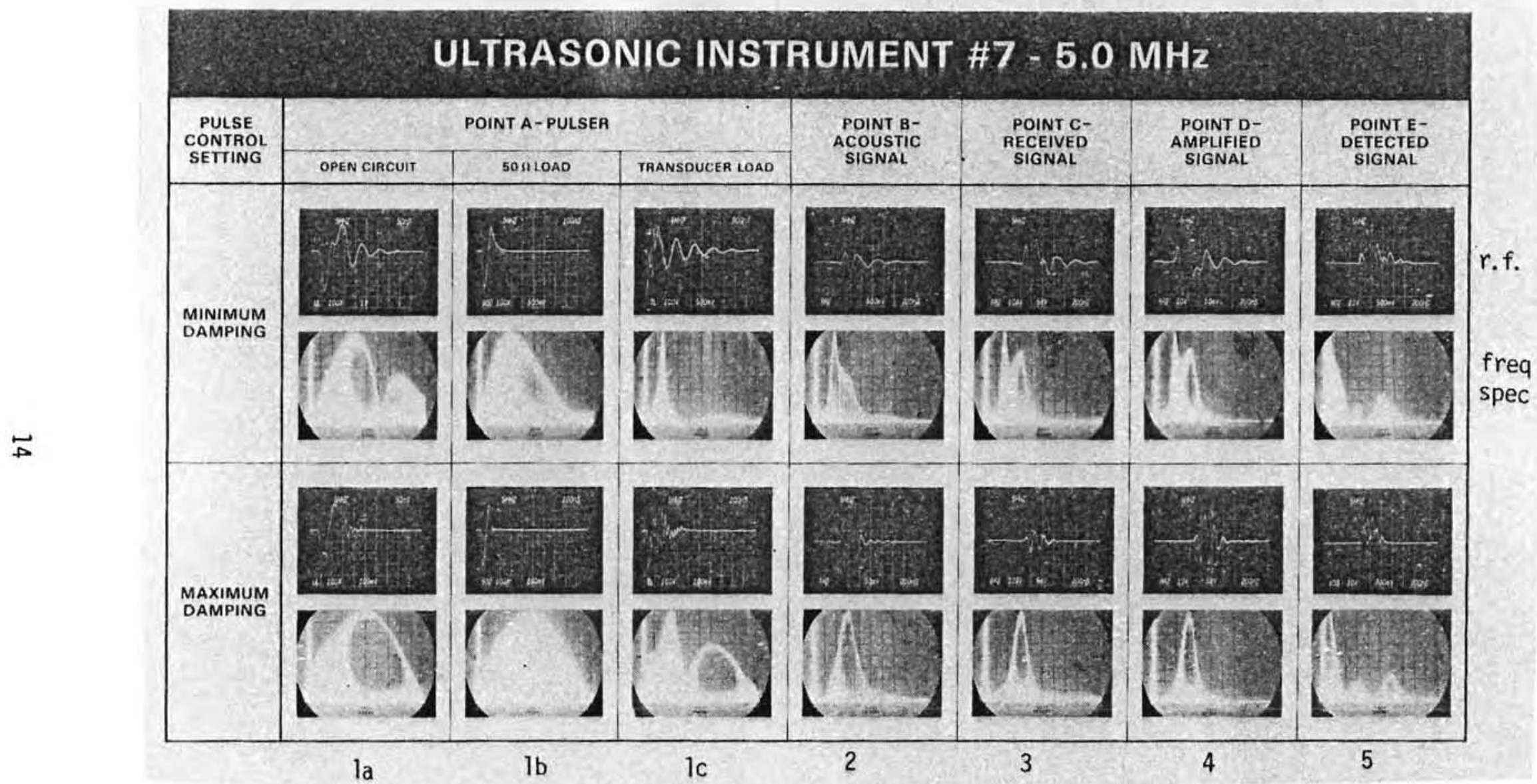

FIGURE 8. Sonic Mark II Instrument Charcterization Measurements for Minimum and Maximum Damping Control 


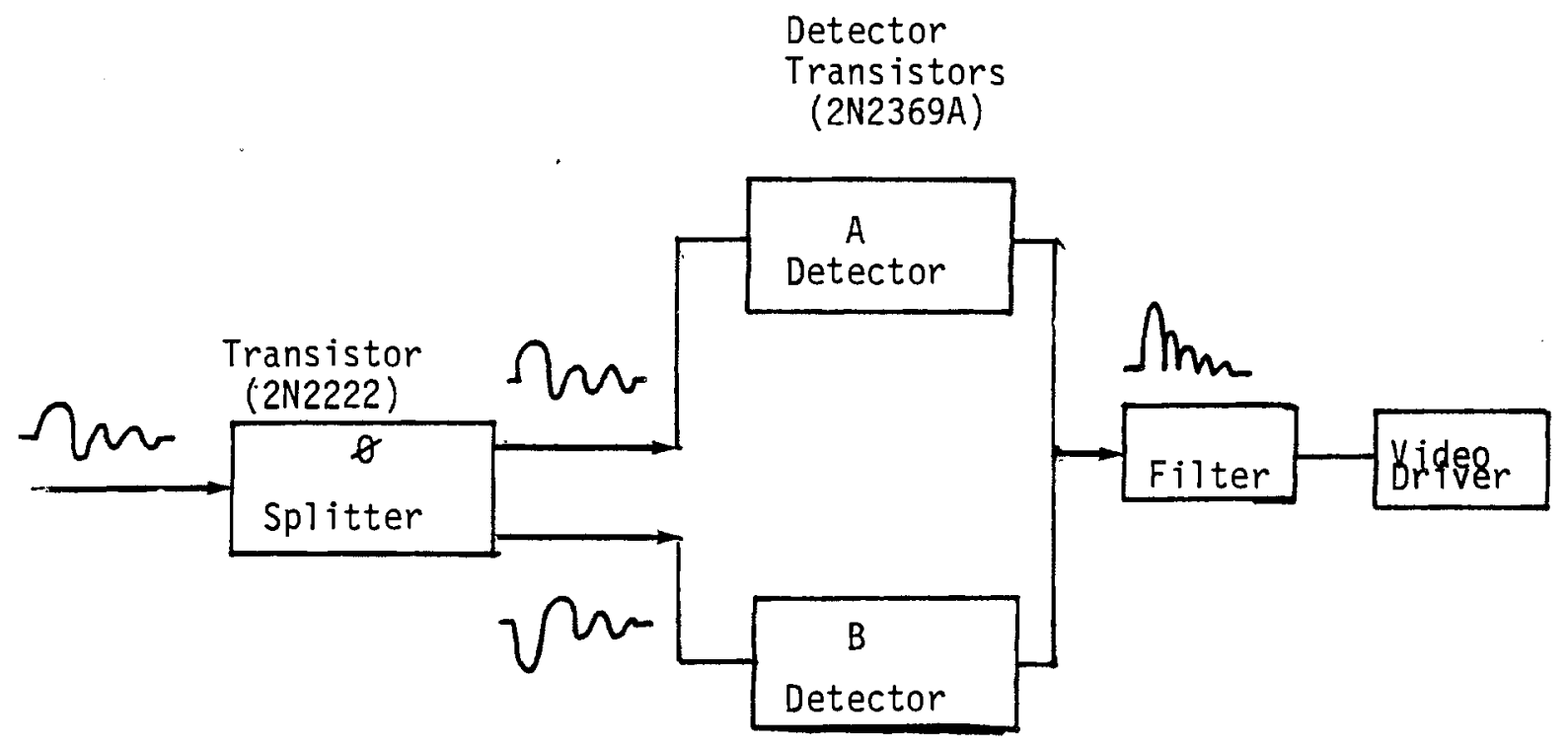

FIGURE 9. Sonic Mark II Detector Circuit

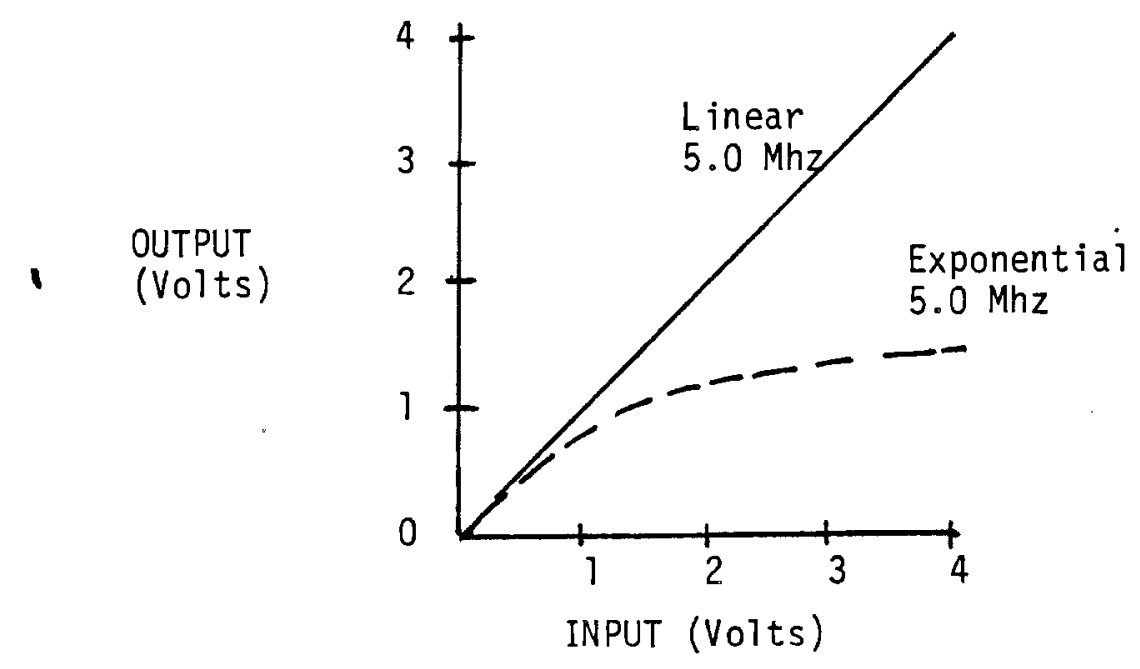

FIGURE 10. Simulated Ultrasonic Instrument Detector Response Curves

one can see that a flaw producing an reflected echo amplitude signal of 4 volts input to the detector (representing large reflectors), would give a detector output of approximately 1 volt, whereas a 2 volt signal (much smaller reflector) would also produce a 1 volt detector output. Therefore, the instrument would lack some capability to distinguish between large reflectors and small reflectors.

Another point to keep in mind is the fact that the input to the detector is comprised of many frequencies (Point $C$ received signal, $6 \mathrm{~dB}$ bandwidth from $2.8 \mathrm{MHz}$ to $7.0 \mathrm{MHz}$ ) each having a particular detector response. 
As you have probably realized by now there are many parameters that can affect the performance of ultrasonic nondestructive evaluation systems. Perhaps the most critical being the quality of the piezoelectric transducers used to generate and detect the ultrasonic signals, and, on the compatibility and response of these transducers with the pulser/receiver electronics. To optimize system performance the system designer should be cognizant of the capabilities and limitations of the transducers selected for each particular application, and, of the characteristics of the ultrasonic system electronics that will elicit the best response from these transducers.

An incomplete summary of the current status of ultrasonic instruments and transducers in use for XM774 and XM833 testing follows. Rocky Flats uses a Tektran Immerscope ultrasonic flaw detection instrument with Panametrics 0.750 -inch spherically focused $5.0 \mathrm{MHz}$ (nominal) transducers. Battelle Columbus uses an Automation Industries 721 ultrasonic flaw detection instrument with Harrisonic $0.75-$ inch spherically focused $5.0 \mathrm{MHz}$ (nominal) transducers. Nuclear Metals is using an Automation Industries S-80 ultrasonic flaw detection instrument and a Sonic Mark II ultrasonic flaw detection instrument. The system at Nuclear Metals uses Aerotech and Nortec 0.50 inch spherically focused $5.0 \mathrm{MHz}$ transducers.

\section{CURRENT NONDESTRUCTIVE TESTING CAPAB ILITY}

Recent demonstration testing at Chamberlain Manufacturing showed that the prototype eddy-current system has the sensitivity to detect a circumferential EDM slot $0.0020 \mathrm{in}$. depth by $0.065 \mathrm{in}$. length in the critical buttress groove section of the core as shown in Table 2. Larger circumferential slots with depths up to 0.0145 were consistently detected in the critical buttress groove section. Recent fracture mechanics results have reported average values of $K_{0}=35$ to $40 \mathrm{KSi}$ in. at $-50^{\circ} \mathrm{F}$. Critical flaw size $\left(\mathrm{a}_{\mathrm{e}}\right)$ in the high stress, buttress groove surface region of the core was calculated to be approximately 0.020 in. The eddy-current system has demonstrated the capability to detect extremely small flaws in finished depleted uranium cores.

Ultrasonic test data has shown that flat-bottom holes, 0.013 in. diameter, at the core centerline, were consistently detected with a flaw signal/noise ratio of 3 to 1 (Figures 11 and 12). Fracture mechanics analysis has shown that the critical size for embedded flaws at the core centerline was approximately 0.200 in. Flaws 0.200 in. are large flaws and would certainly be detected with current ultrasonic inspection techniques in use. Albeit flaws 0.200 in. are large flaws, however, cracks, stringers, agglomerations of voids and leftover casting defects have occurred in the manufacture of depleted uranium cores.

Examples of nondestructive-destructive verification testing results from a "quick water quenched" depleted uranium penetrator (no. 86) are shown in Figures 13 to 19. 
TABLE 2. Eddy Current Calibration Standard No. BNW47B

\begin{tabular}{|c|c|c|c|c|c|c|}
\hline \multirow{3}{*}{$\begin{array}{l}\text { Core } \\
\text { Location } \\
\text { Front } \\
\text { Section }\end{array}$} & \multirow{3}{*}{$\begin{array}{c}\frac{\text { Slot }}{M} \\
L \\
K\end{array}$} & & & \multicolumn{3}{|c|}{ Eddy Current Signal $(c)$} \\
\hline & & $\begin{array}{l}\text { Planned (a) } \\
\text { Defect Size }\end{array}$ & $\begin{array}{l}\text { Measured (b) } \\
\text { Actual Size }\end{array}$ & $\begin{array}{l}\text { Defect } \\
\text { Ch. } 2\end{array}$ & $\begin{array}{l}\text { Ch. } 2 \\
\text { Noise }\end{array}$ & $\begin{array}{l}\text { Defect } \\
\text { Ch. } 1\end{array}$ \\
\hline & & $\begin{array}{l}0.005 \times 0.060(1) \\
0.005 \times 0.125(-) \\
0.005 \times 0.125(1)\end{array}$ & $\begin{array}{l}0.0097 \times 0.130 \\
0.0056 \times 0.080 \\
0.0065 \times 0.13\end{array}$ & $\begin{array}{r}18 \\
7 \\
10\end{array}$ & $\begin{array}{l}3 \\
3 \\
3\end{array}$ & $\begin{array}{l}5 \\
4 \\
5\end{array}$ \\
\hline $\begin{array}{l}\text { Groove } \\
\text { Section }\end{array}$ & $\begin{array}{r}3 \\
7 \\
11 \\
15 \\
19 \\
23 \\
27 \\
31 \\
35\end{array}$ & $\begin{array}{l}0.003 \times 0.060(1) \\
0.020 \times 0.060(1) \\
0.010 \times 0.060(1) \\
0.005 \times 0.030(1) \\
0.005 \times 0.060(1) \\
0.005 \times 0.125(1)\end{array}$ & $\begin{array}{l}0.0111 \times 0.130 \\
0.006 \times 0.125 \\
0.0053 \times 0.130 \\
0.0020 \times 0.065 \\
0.0145 \times 0.060 \\
0.0108 \times 0.050 \\
0.0068 \times 0.025 \\
0.0056 \times 0.050 \\
0.0055 \times 0.115\end{array}$ & $\begin{array}{r}24 \\
13 \\
13 \\
6 \\
29 \\
22 \\
5 \\
10 \\
16\end{array}$ & $\begin{array}{l}5 \\
5 \\
5 \\
5 \\
5 \\
5 \\
5 \\
5 \\
5\end{array}$ & $\begin{array}{r}9 \\
7 \\
7 \\
4 \\
11 \\
5 \\
0 \\
5 \\
6\end{array}$ \\
\hline $\begin{array}{l}\text { Rear } \\
\text { Section }\end{array}$ & $\begin{array}{l}J \\
H \\
G\end{array}$ & $\begin{array}{l}0.010 \times 0.125(1) \\
0.005 \times 0.125(-) \\
0.005 \times 0.125(1)\end{array}$ & $\begin{array}{l}0.0098 \times 0.125 \\
0.0057 \times 0.130 \\
0.0058 \times 0.125\end{array}$ & $\begin{array}{r}24 \\
8 \\
10\end{array}$ & $\begin{array}{l}4 \\
4 \\
4\end{array}$ & $\begin{array}{r}12 \\
4 \\
5\end{array}$ \\
\hline
\end{tabular}

(a) Depth $\times$ length slot (all slots 0.005 wide).

(b) Optical technique used.

(c) Data recorded using a Brush 220, 2 channel recorder.

(1) circumferential slot

(-) axial slot

The figures show (top to bottom), (a) the ultrasonic flaw amplitude response for voids with the Sonic Mark II set to $67 \mathrm{~dB}$ gain, $5 \mathrm{MHz}$ spherically focused transducer, $50 \mathrm{mv} / \mathrm{minor}$ division; (b) enlarged photographic picture of void showing geometric detail $X$ and $Y$ coordinate dimensions to assess void size; and (c) photograph of 4-in. specimen taken during destructive sectioning (arrow indicates void location along the core axis).

The sectioning work entailed the use of an end mill to make multiple metal cuts using two 4-in. long specimen sections. One section from the would be nose of the penetrator, the other specimen from the rear section. Data showing the extent of these flaws in the $Z$ direction (transverse) was determined by keeping a record of the amount of material removed during each cut. A review of the photographs showed that the majority of the larger porosity was 50 to $80 \mathrm{mils}(1 \mathrm{mil}=0.001 \mathrm{in}$.) in the $z$ direction.

With a Mark II instrument gain of $66 \mathrm{~dB}$, using a $5 \mathrm{MHz}$ spherically focused transducer, with the Brush 220 set to $50 \mathrm{MV} / \mathrm{minor}$ division flaw echo amplitude is $80 \%$ or greater of the full-scale deflection as shown in Figures 13 to 15. Note these voids are all 0.100 in. or greater in either $X$ or $Y$ dimension. Figures 16 to 18 show an agglomeration of voids that produce a flaw echo amplitude response of $50 \%$ of full-scale deflection. Single voids are approximately 


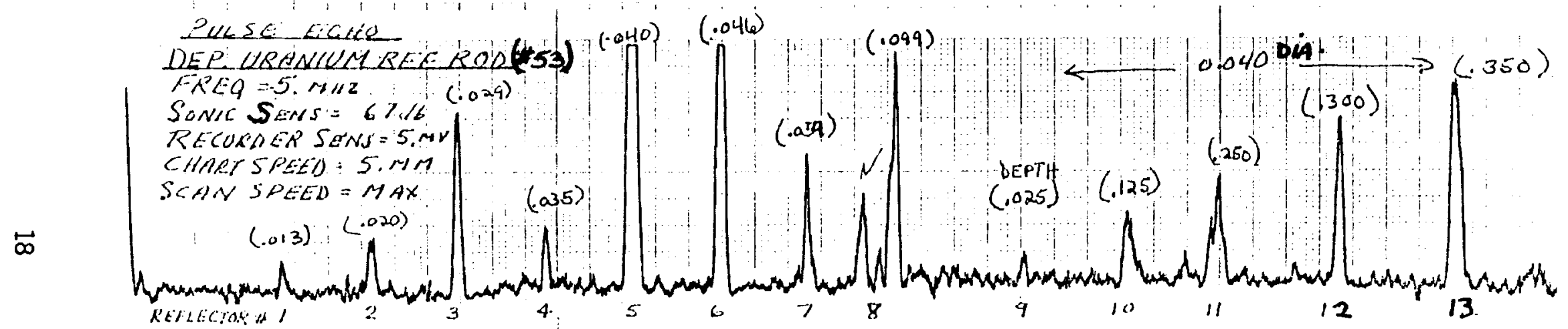

FIGURE 11. Ultrasonic Pulse-Echo Response from Depleted Uranium Core no. 53 (fab. at Sandia Labs). 
REFERENCE ROD \#53, BNW-0001, BNW-0002

(for Pulse Echo U.T. Ref)

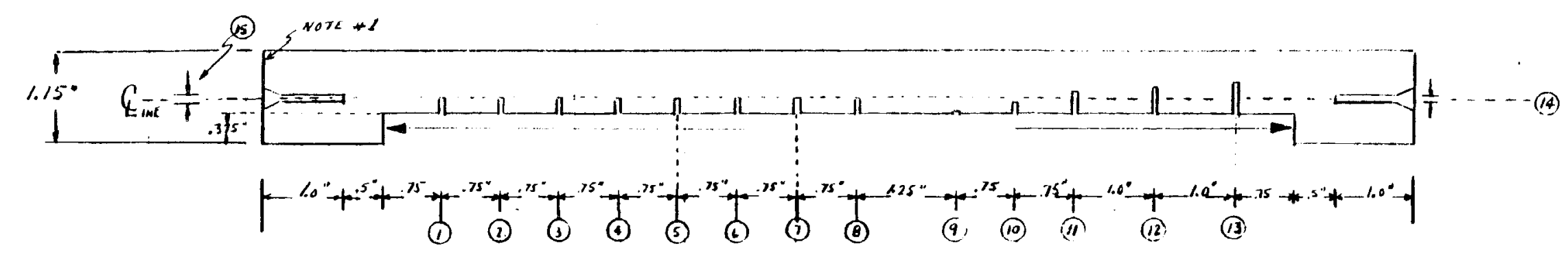

\begin{tabular}{|c|c|c|}
\hline Hob & HSULE & $\Omega(\theta, u x)$ \\
\hline (1) & 80 & .0135 \\
\hline 2 & 16 & .020 \\
\hline j & 69 & .029 \\
\hline 4 & . 65. & .035 \\
\hline 5 & $60^{\circ}$ & .040 \\
\hline 6 & 56 & .0465 \\
\hline 7 & 53 & 0595 \\
\hline 8 & 37 & .0985 \\
\hline 9 & 60 & .040 \\
\hline $\overrightarrow{0}^{10}$ & be & .040 \\
\hline 11 & $\therefore 0$ & .040 \\
\hline 12 & 60 & .040 \\
\hline 13 & 00 & .040 \\
\hline 14 & 5 & .0595 \\
\hline 15 & 60 & .040 \\
\hline
\end{tabular}

OENTEleN
.20
.20
20
.20
.20
.20
.20
.20
.025
.125
.250
.300
.375
.750
.750
MATL = DEPLETED LIRANIUN (HEAT TREATED)$$
1 \text { em } P<Q^{\circ} 0
$$
$\angle U C / T E$

SPECIAL NOTE

THIS DRAWING WILL BSE USEO TO FHOBISHTE 2 REFERENCE ROOS OF LUSITE $\div$ WILL BE NUMGERER BNW OOOI \& BNW

.750 SENGIA' (ANST CENTEAING HOLEL

$.750 \leq E N G T H$ (PAST CONEPNA HLLE)

WTE \#L END CUT OFF SQUARE

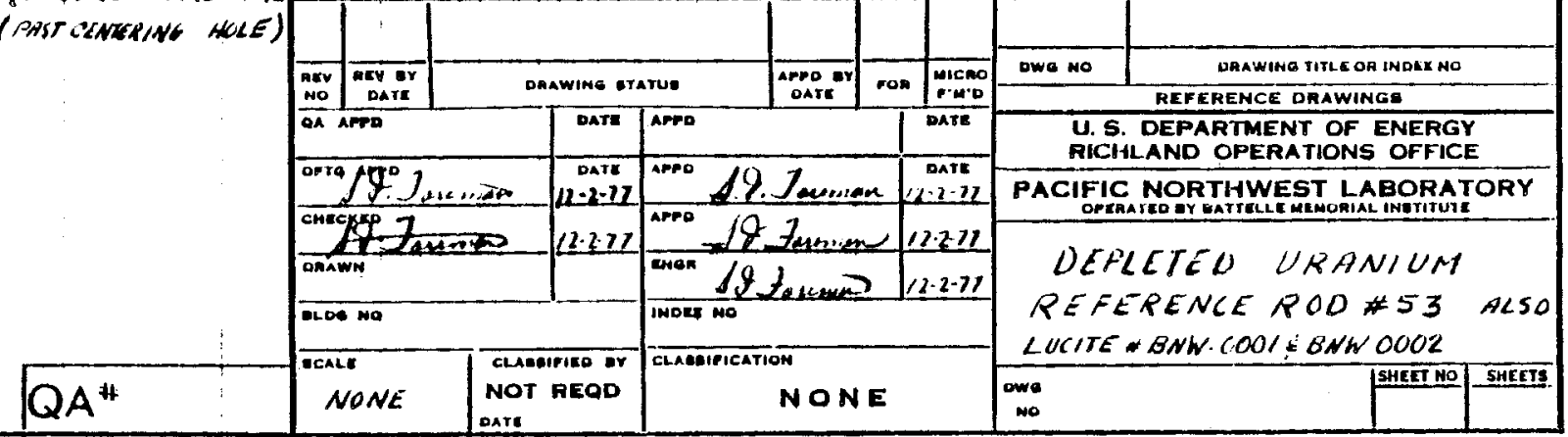

FIGURE 12. Depleted Uranium Core no. 53 

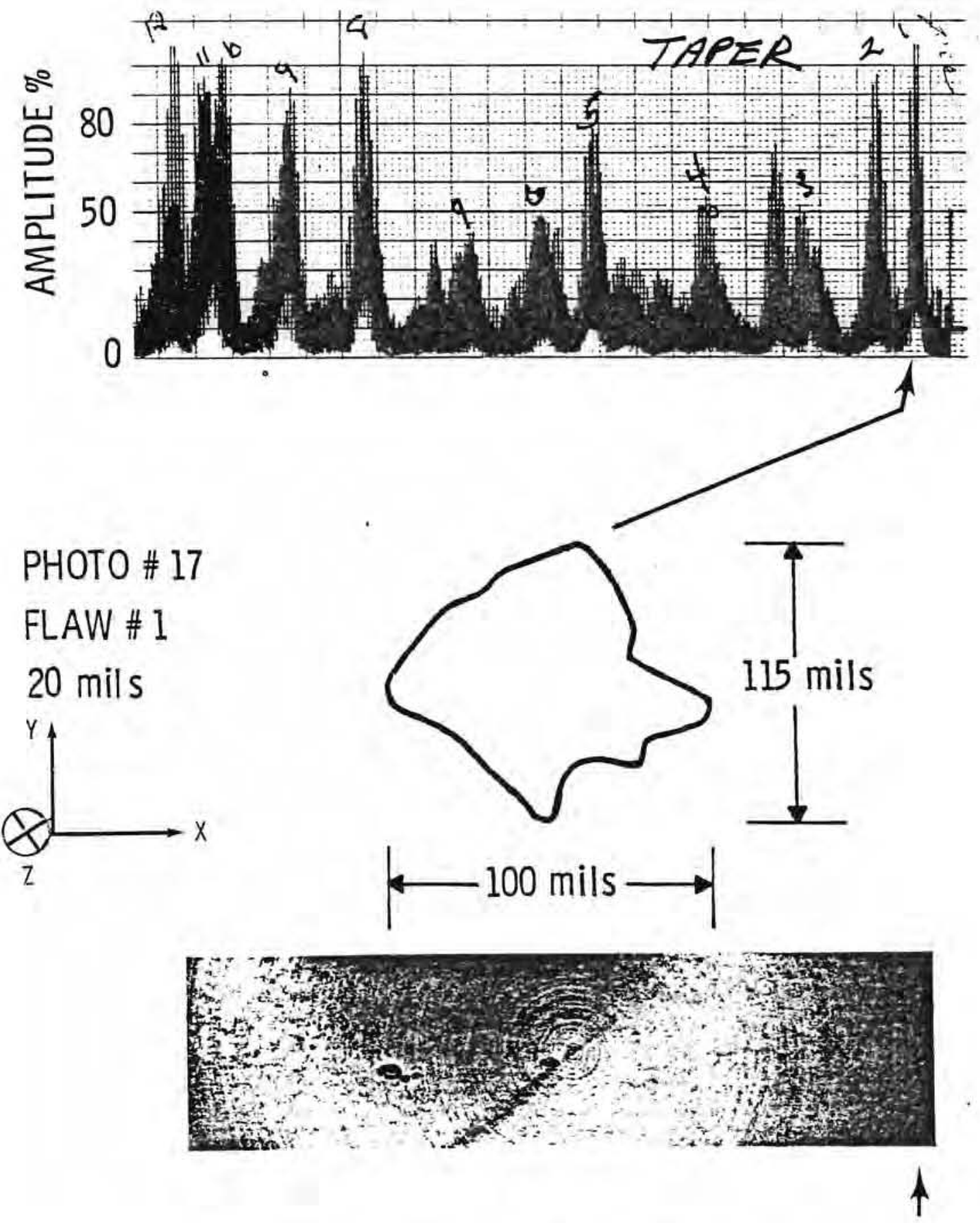

FIGURE 13. Depleted Uranium Core no. 86 


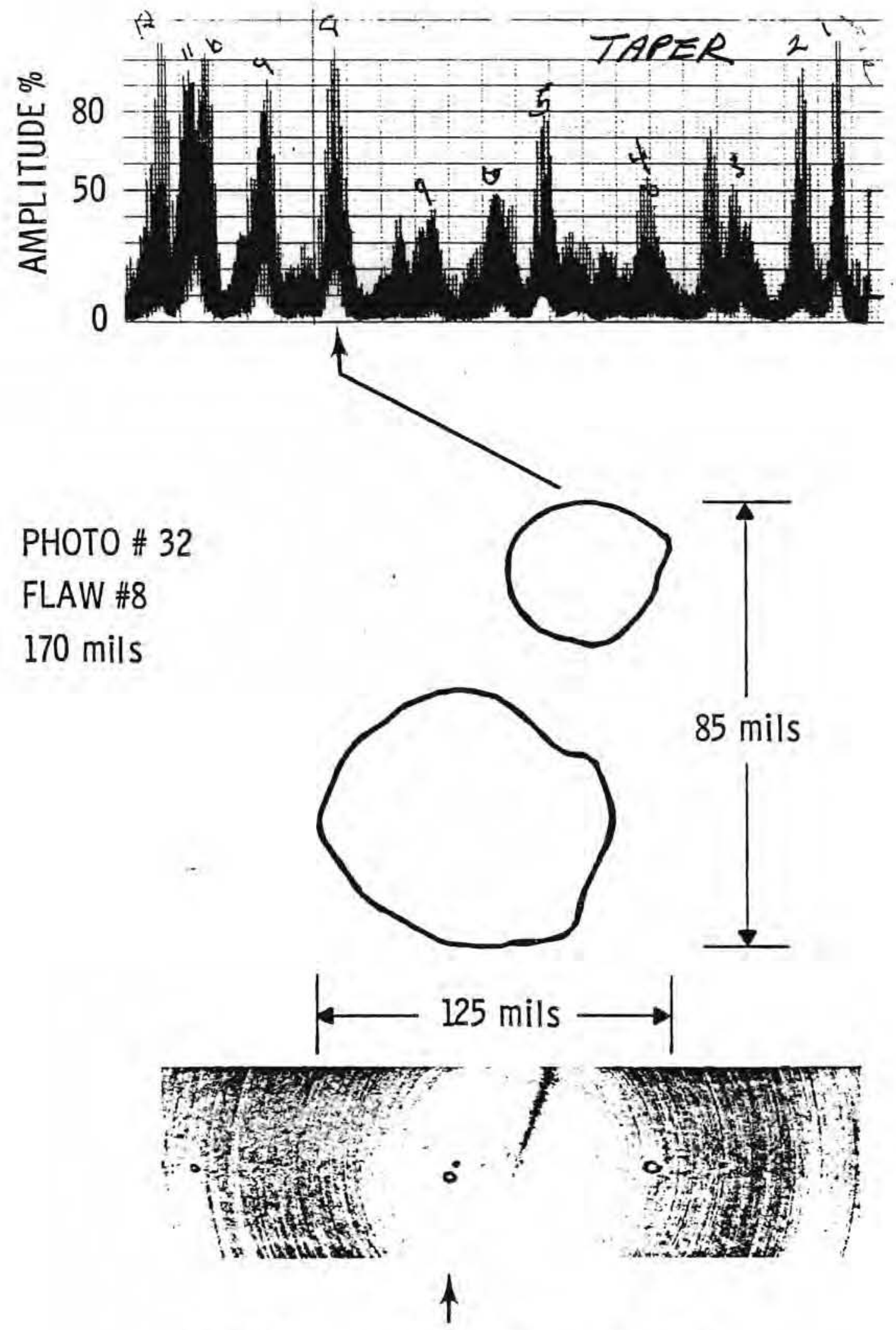

FIGURE 14. Depleted Uranium Core no. 53 


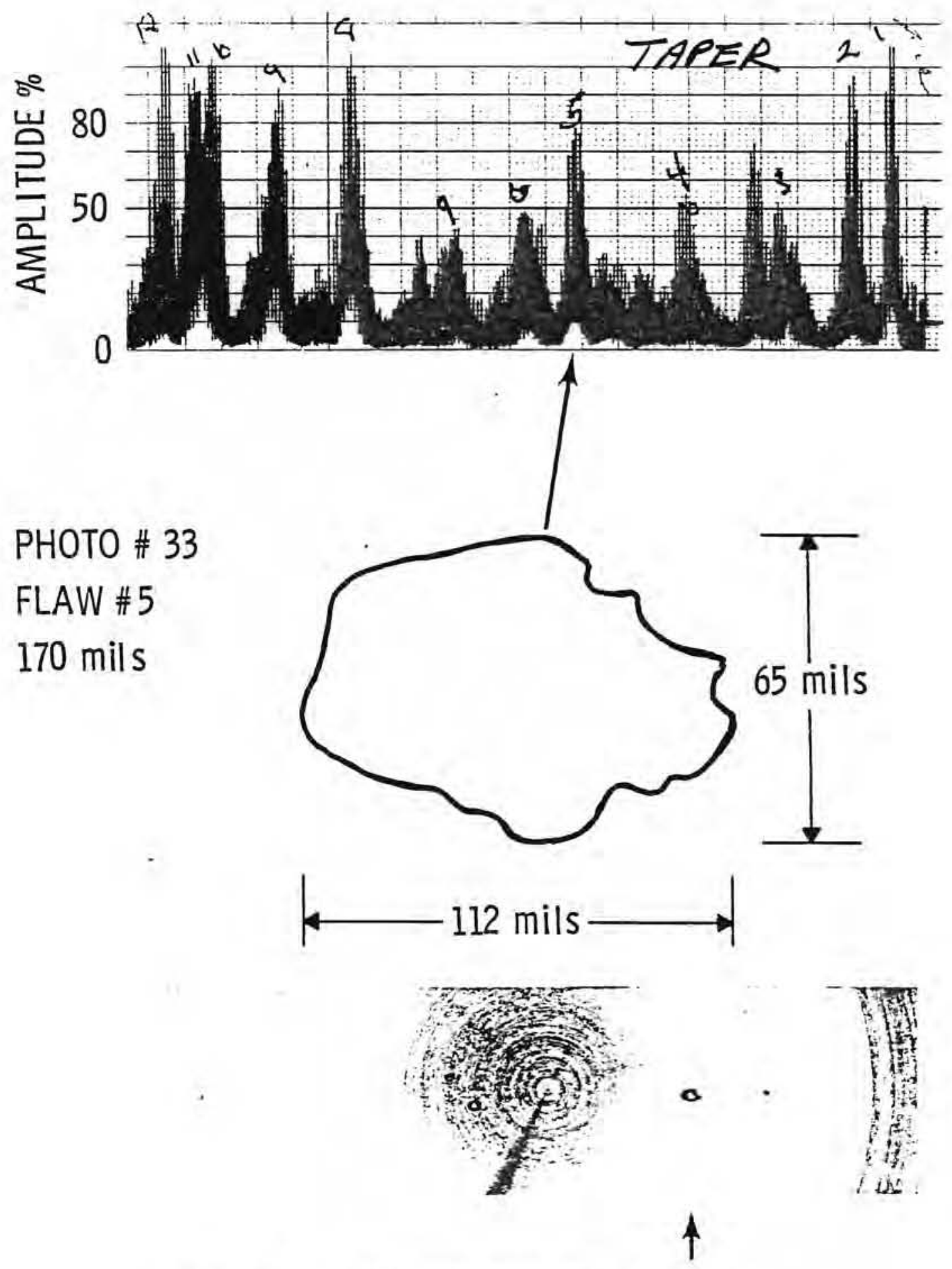

FIGURE 15. Depleted Uranium Core no. 86 


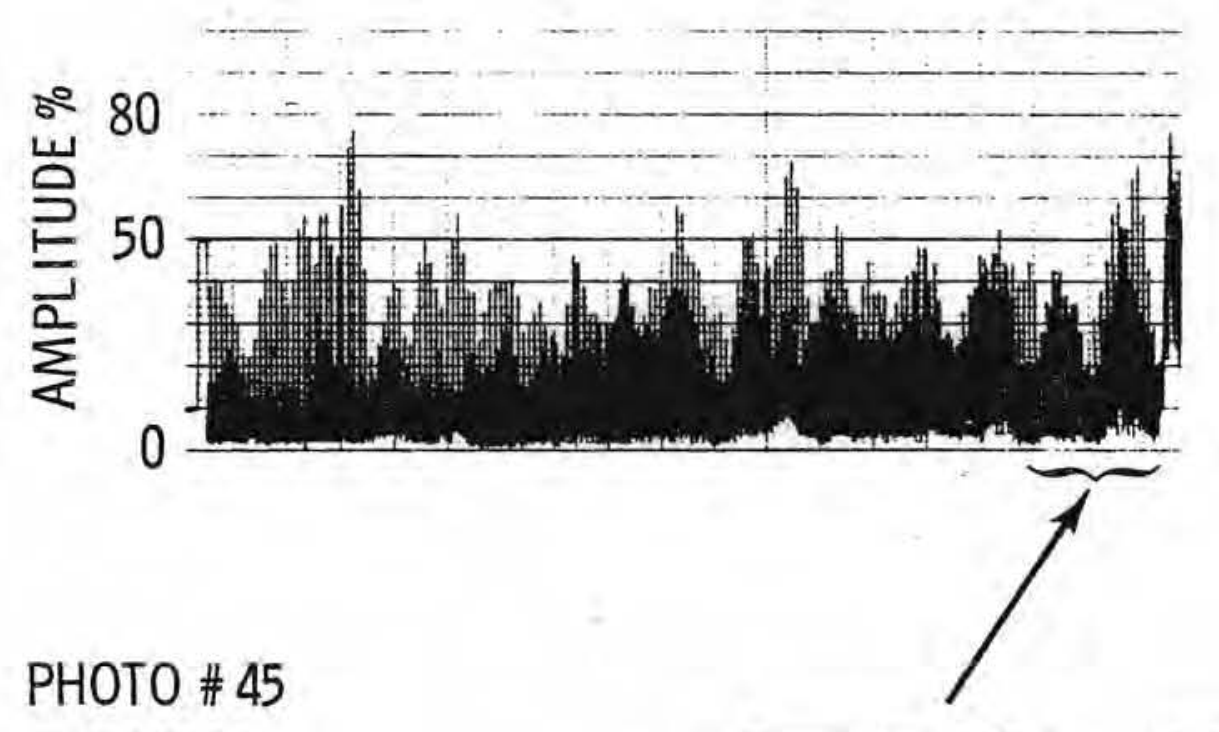

FLAW \# 13

70 mils
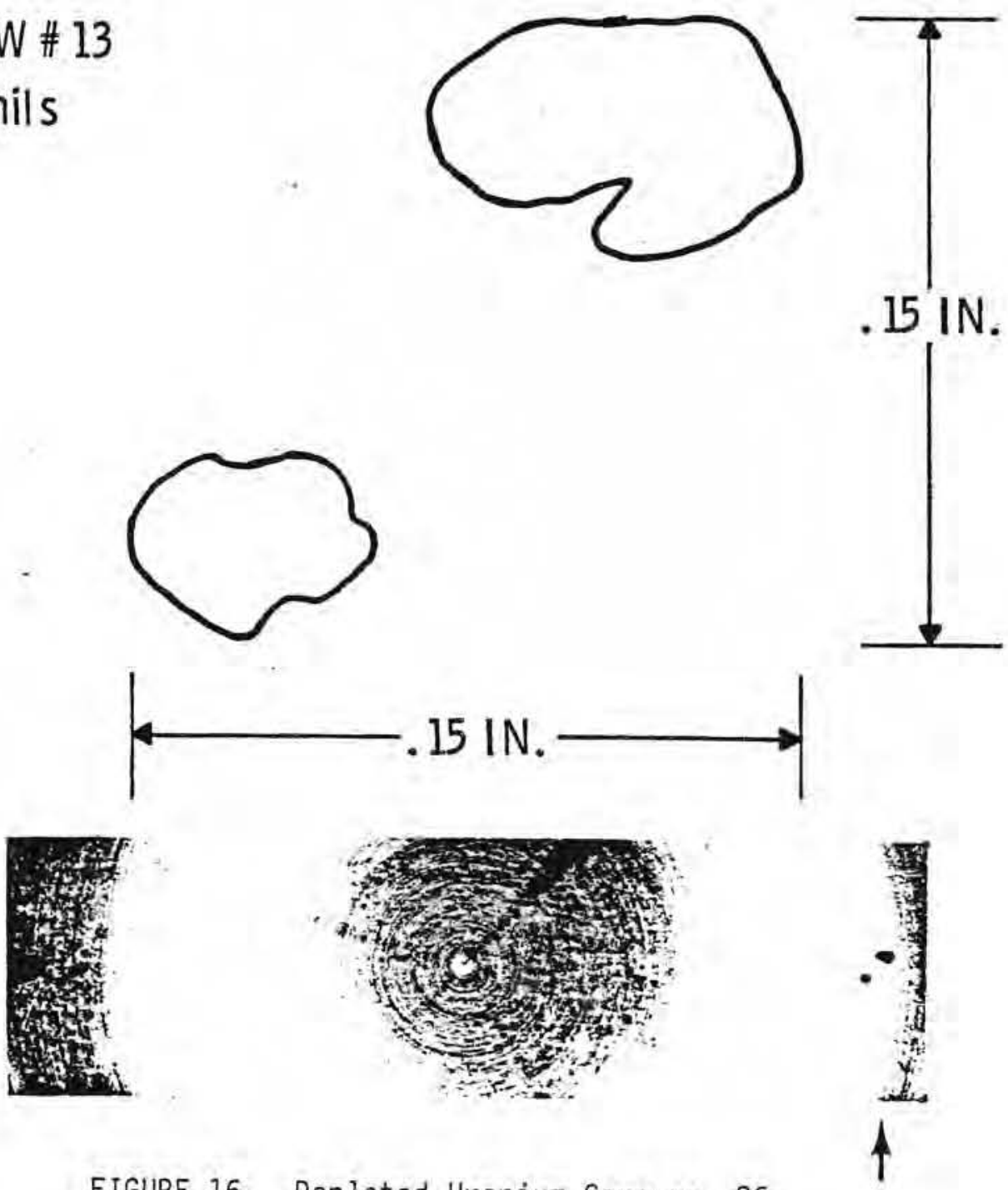

FIGURE 16. Depleted Uranium Core no. 86 


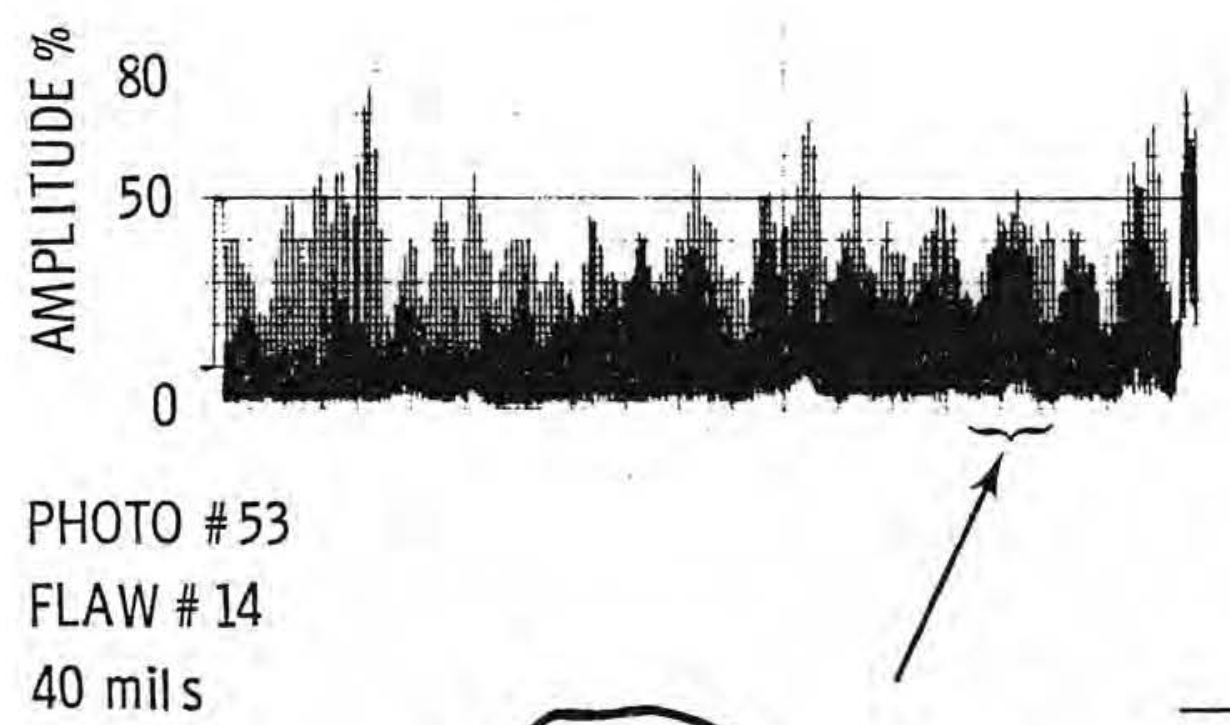

FLAW \# 14 40 mils
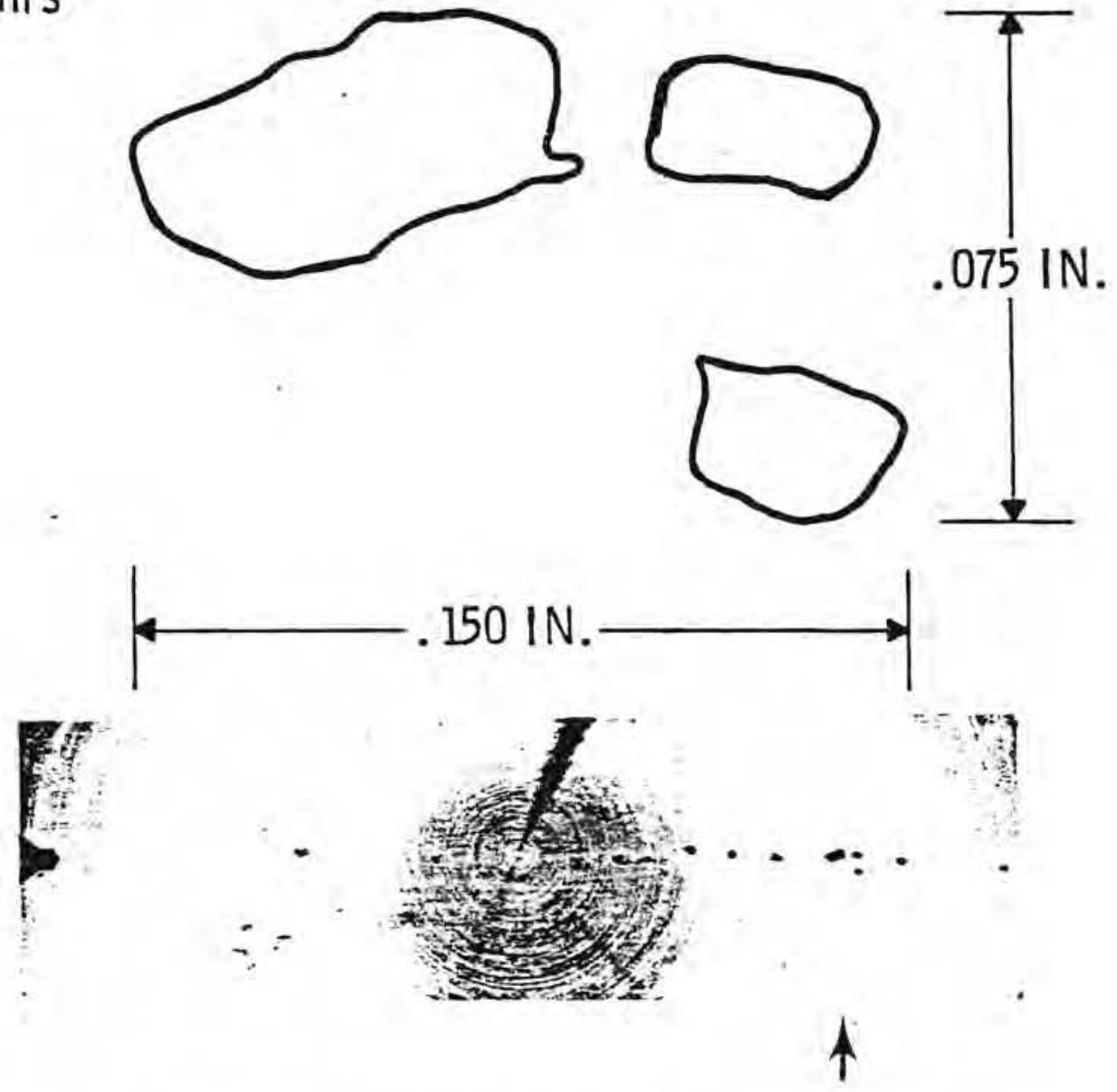

FIGURE 17. Depleted Uranium Core no. 86 

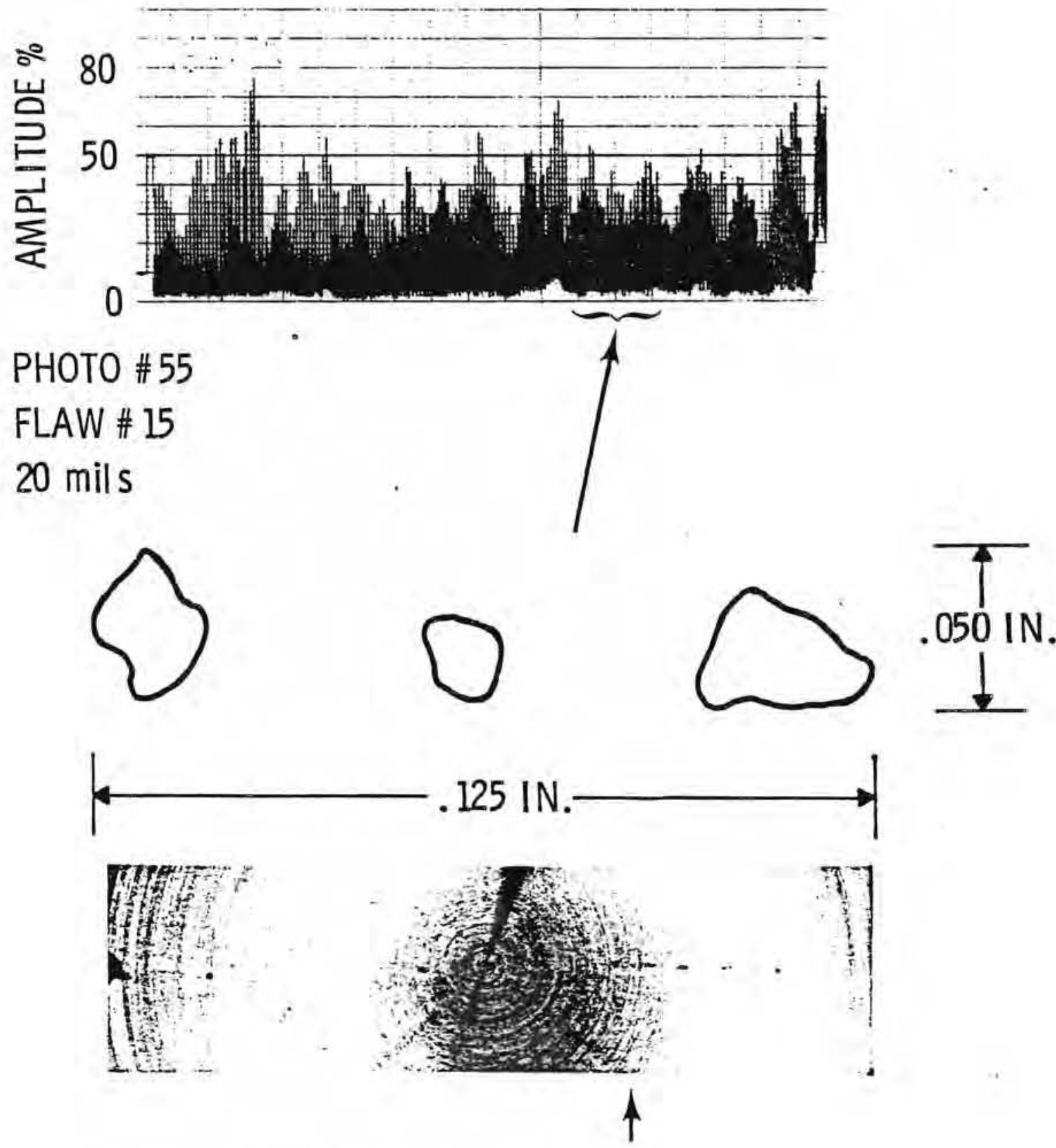

FIGURE 18. Depleted Uranium Core no. 86 
0.050 to $0.070 \mathrm{in}$. in the $x$ dimension, and approximately 0.050 in. or less in the $Y$ dimension. Figure 19 shows a $50 \%$ echo amplitude indication from a single void $0.050 \mathrm{in}$. by $0.035 \mathrm{in}$.

Figures 20 to 26 show additional nondestructive-destructive confirmatory data for core numbers: 212 (casting defect), 187 (OD crack), 621-1 (ID crack) (a) and 169 (extrusion defect). (b) Ultrasonic pulse-echo, offset, shear and back surface data is presented for instrument settings of Mark II gain at $67 \mathrm{~dB}$ at $5 \mathrm{MHz}$ narrowband pulser/receiver setting, spherically focused $5 \mathrm{MHz}$ transducer, Brush 220 at $10 \mathrm{mv} / \mathrm{minor}$ division ( 5 times the recorder sensitivity used in recording ultrasonic data for core no. 86 .

Figure 20 shows the ultrasonic inspection results for core no. 212 containing a leftover casting defect located at the end of the core. This defect is located about the core centerline as shown in Figure 21. The pulse-echo normal beam test (Figure 20a) showed a strong flaw signal indication, as did the loss of back signal test in Figure 20e. The casting defect was approximately 3 in. in length with the sectioning results shown in Figure 22 .

Figure 23 shows the 47 trasonic inspection results for core no. 187 . This core had two cracks on the outer diameter and was detected by the off set inspection technique as shown in Figure 23a. The shear inspection results are shown in Figure $23 \mathrm{c}$ and $23 \mathrm{~d}$. These data show flaw signal indications which are interesting considering the crack was approximately 0.100 in. deep and never favorably oriented with respect to the 45 degree refracted shear angle. Figure 24 shows core no. 187 with the larger surface crack shown and, approximately 4 in. in length.

(a) Destructive data not included.

(b) Ultrasonic data not included. 

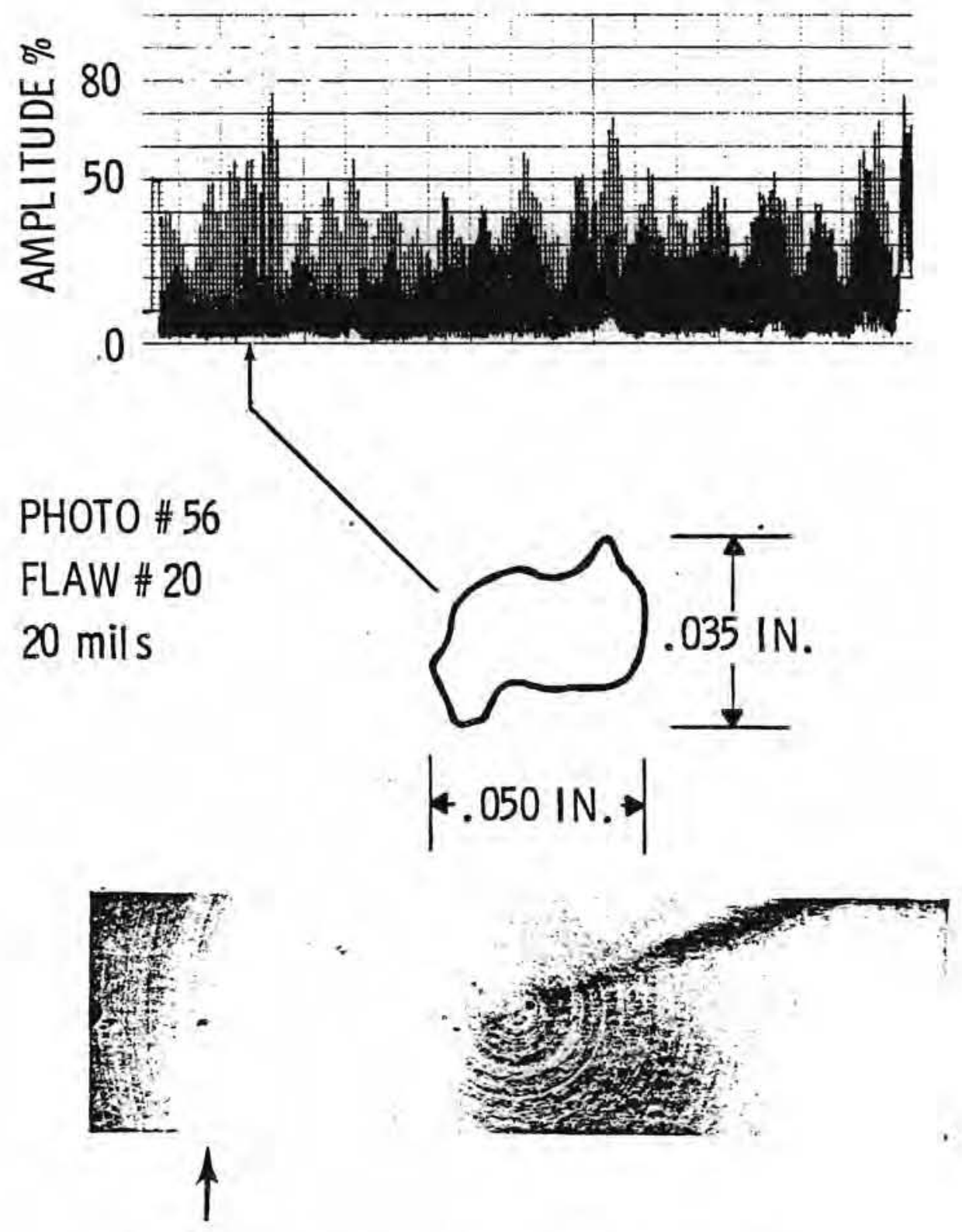

FIGURE 19. Depleted Uranium Core no. 86 


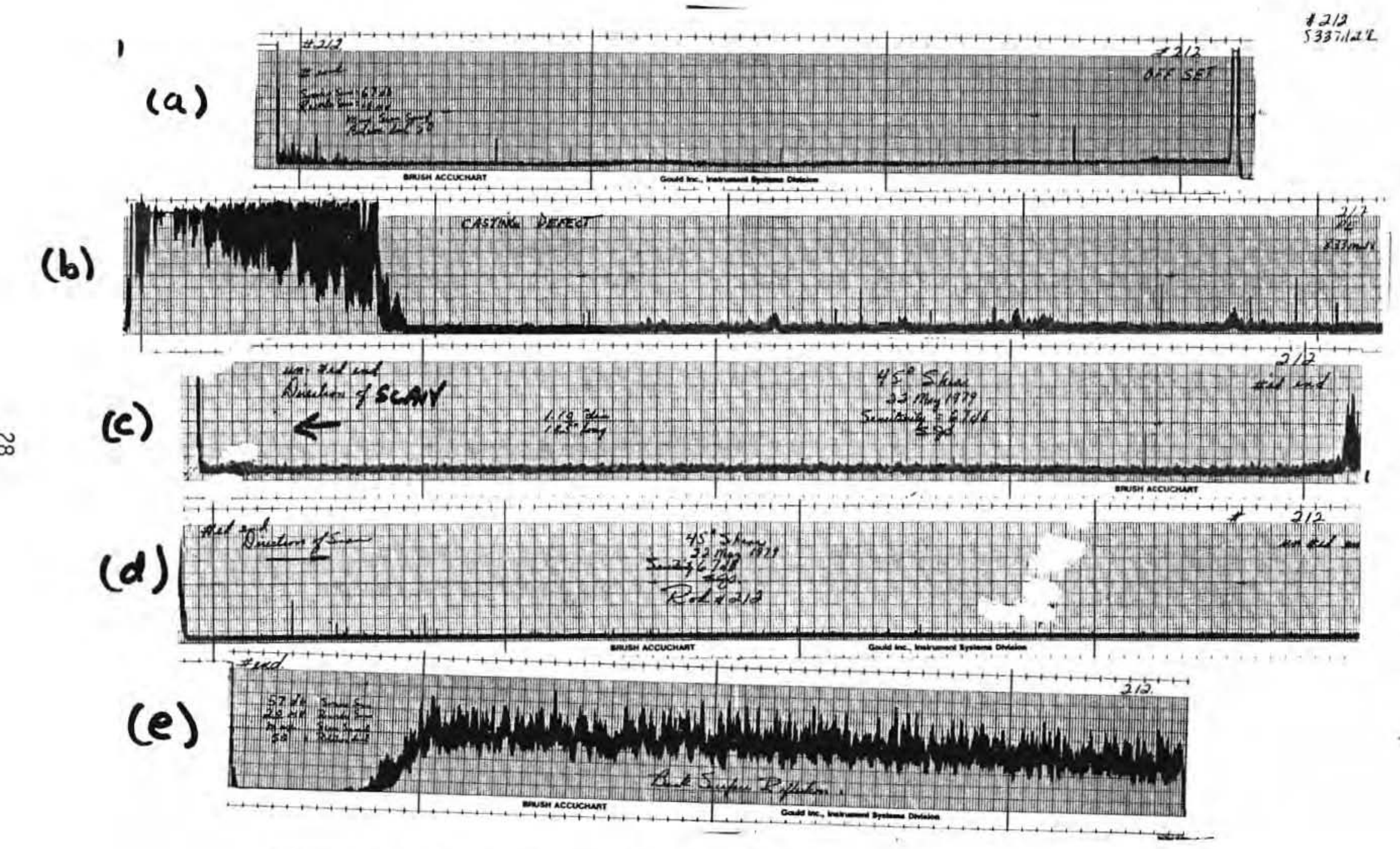

FIGURE 20. Ultrasonic Inspection Results Core no. 212 with Casting Defect 


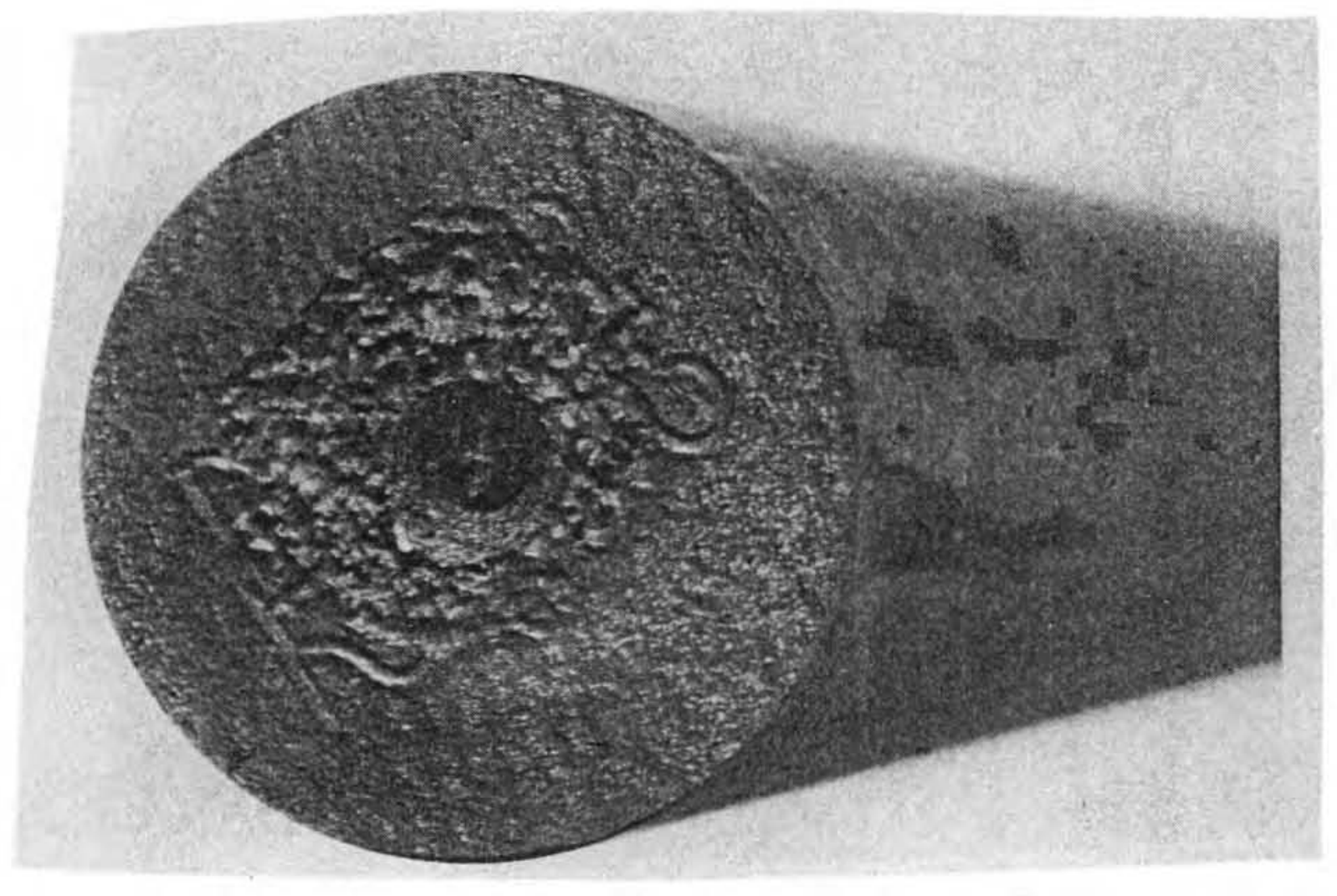

FIGURE 21. Core no. 212 (casting defect) as Received 


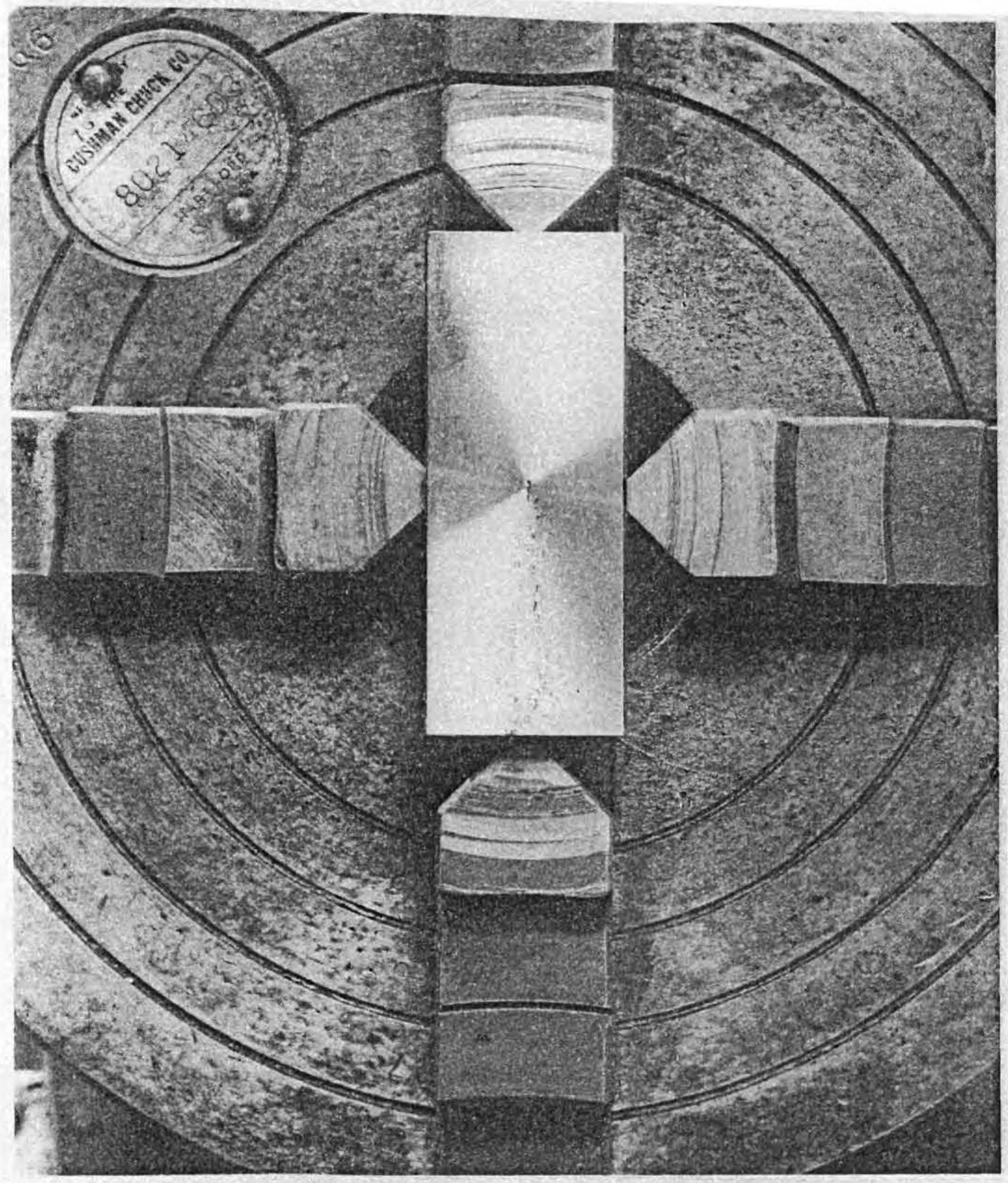

FIGURE 22. Core no. 212 (casting defect), Centerline Section (defect length 3 in.) 
* 187 mall

(a)
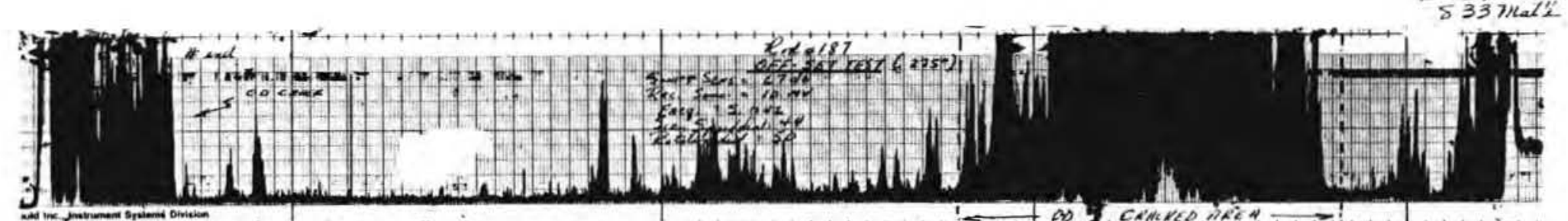

(b)
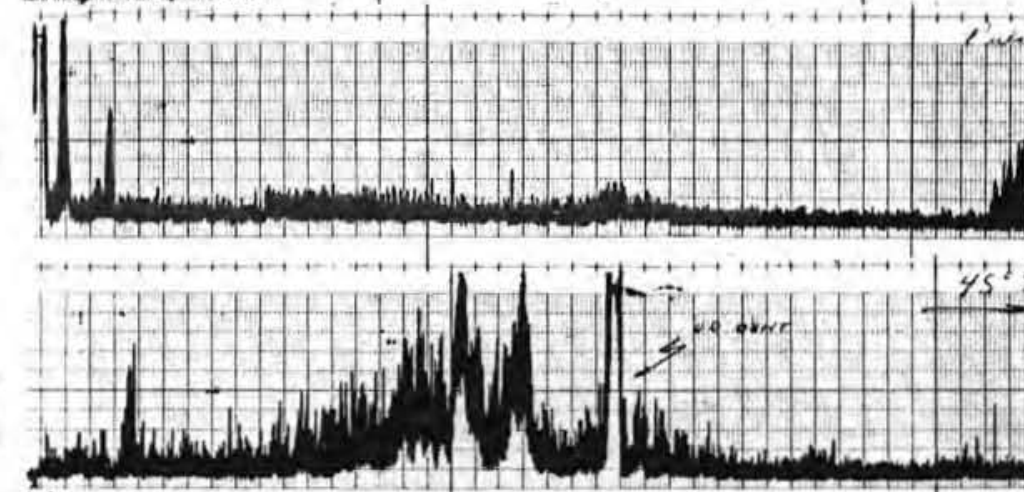
ind $1+1,1+1,1+$ .

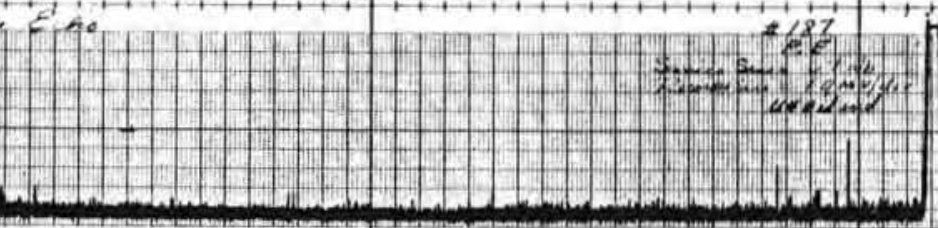

w (c)

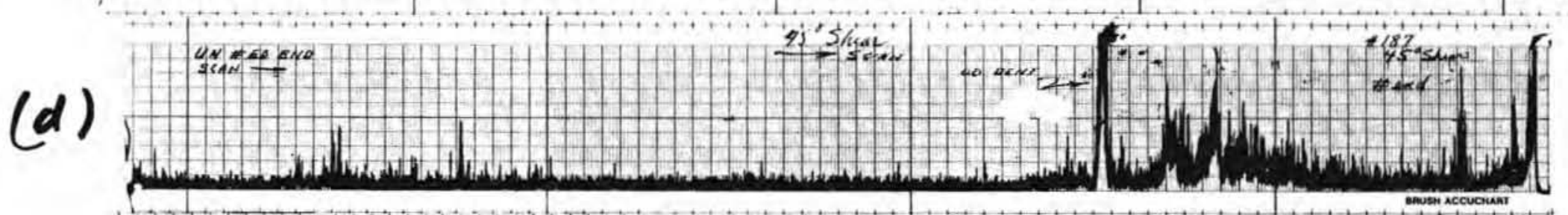

(e)

FIGURE 23. U1trasonic Inspection Results for Core no. 187, Outer Diameter Crack 


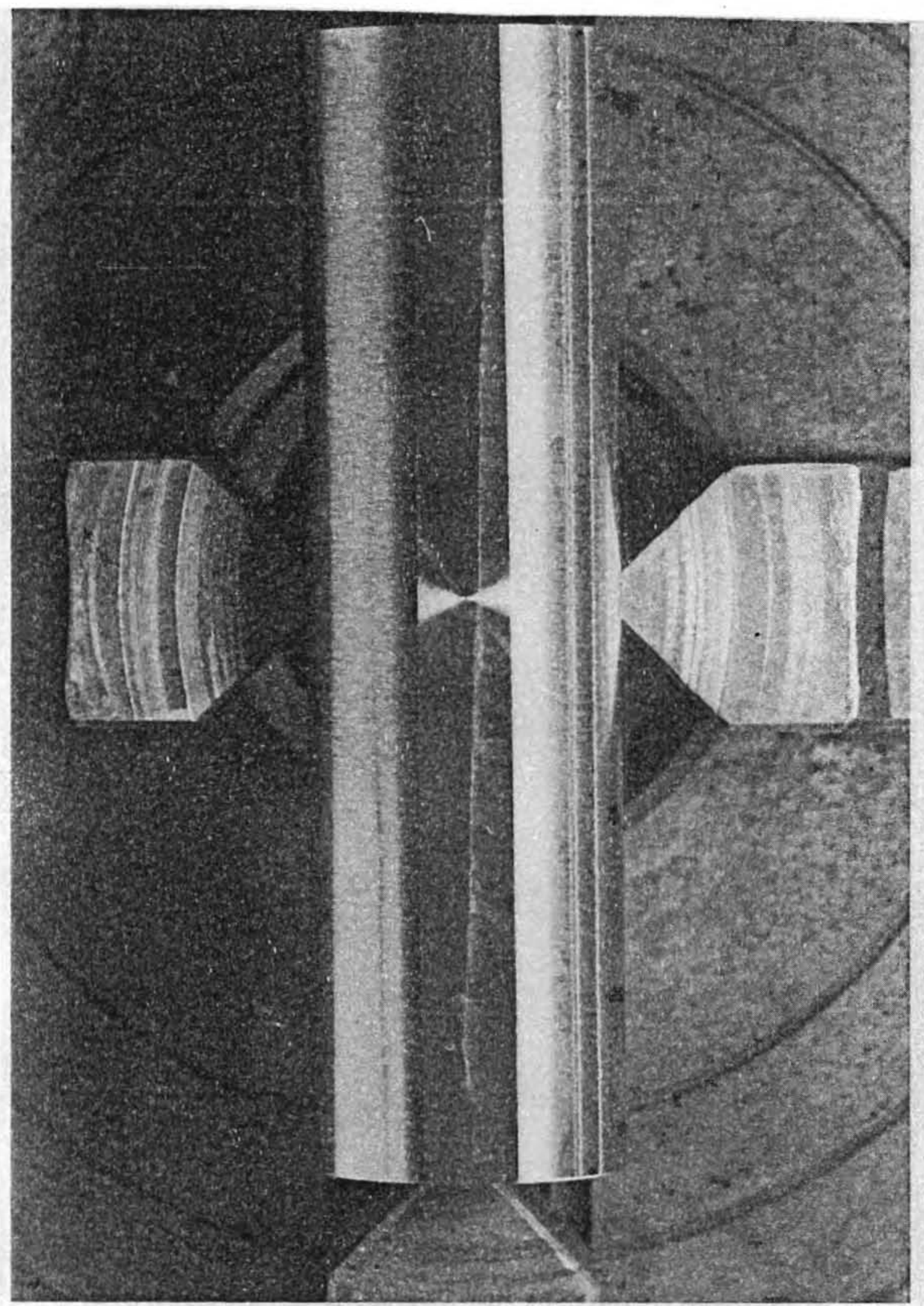

FIGURE 24. Core 187 0.D. Crack, Specimen Approximately 4 in. Length 
Figure 25 shows the ultrasonic inspection results for core no. 621-1. This core contained a large crack that propagated through the full diameter of the core for approximately 6 in. Strong signal indications were recorded for each test as shown in Figure 25.

Figure 26 shows a centerline section view of an extrusion defect approximately 2 in. in length from core no. 169. Although not shown, the ultrasonic test results showed a strong signal indication (full-scale deflection) all along the extent of the extrusion defect. 
(a)

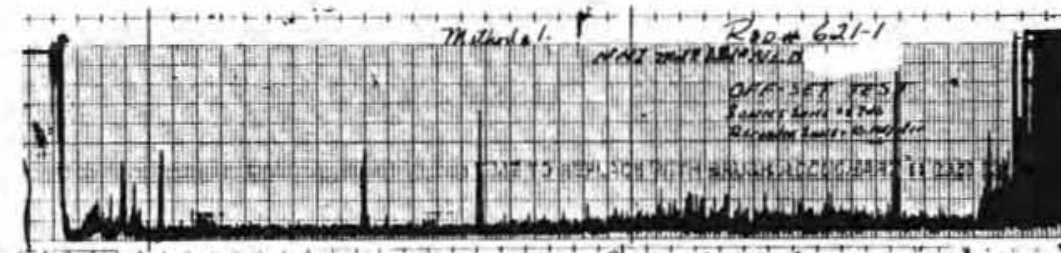

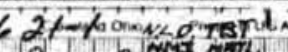
inist in

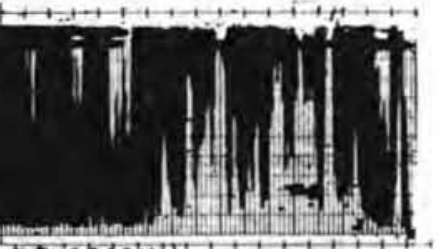
Mnwill in alu menn

(c) (c) .

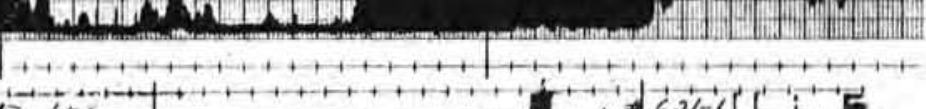

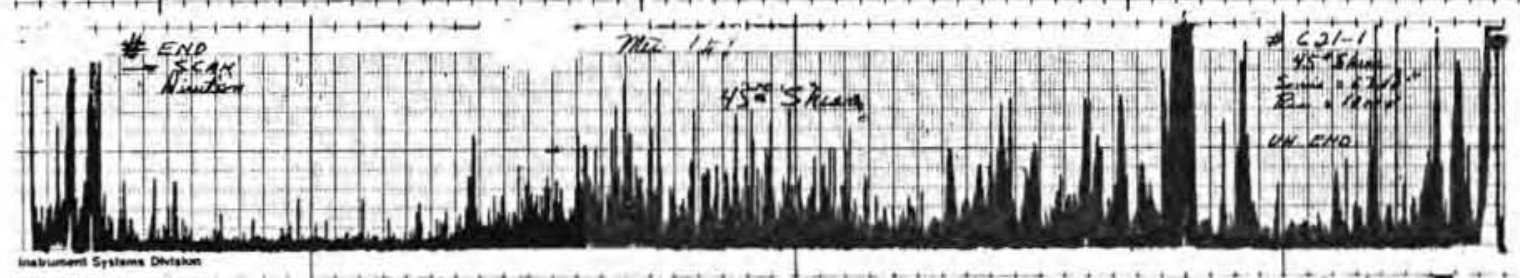

(a)

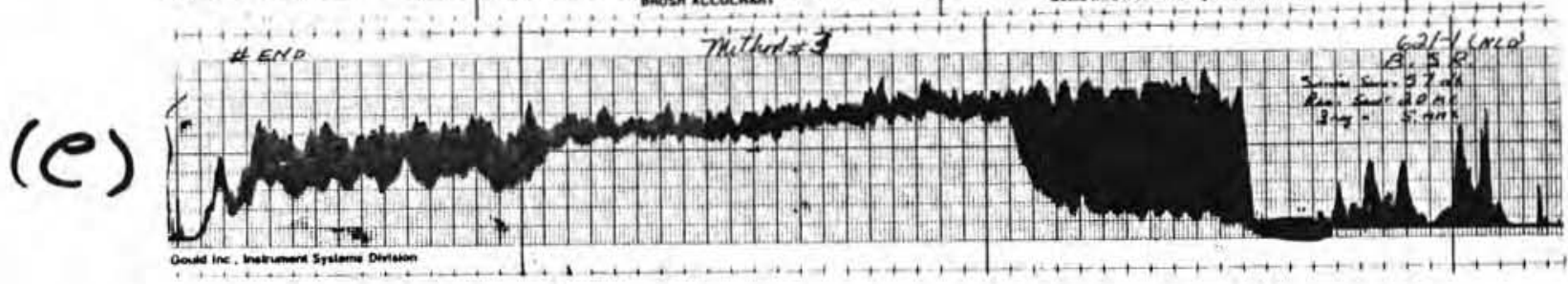

FIGURE 25. U1trasonic Inspection Results for Core no. 621-1 with an Embedded Crack Approximately 6 in. Length 


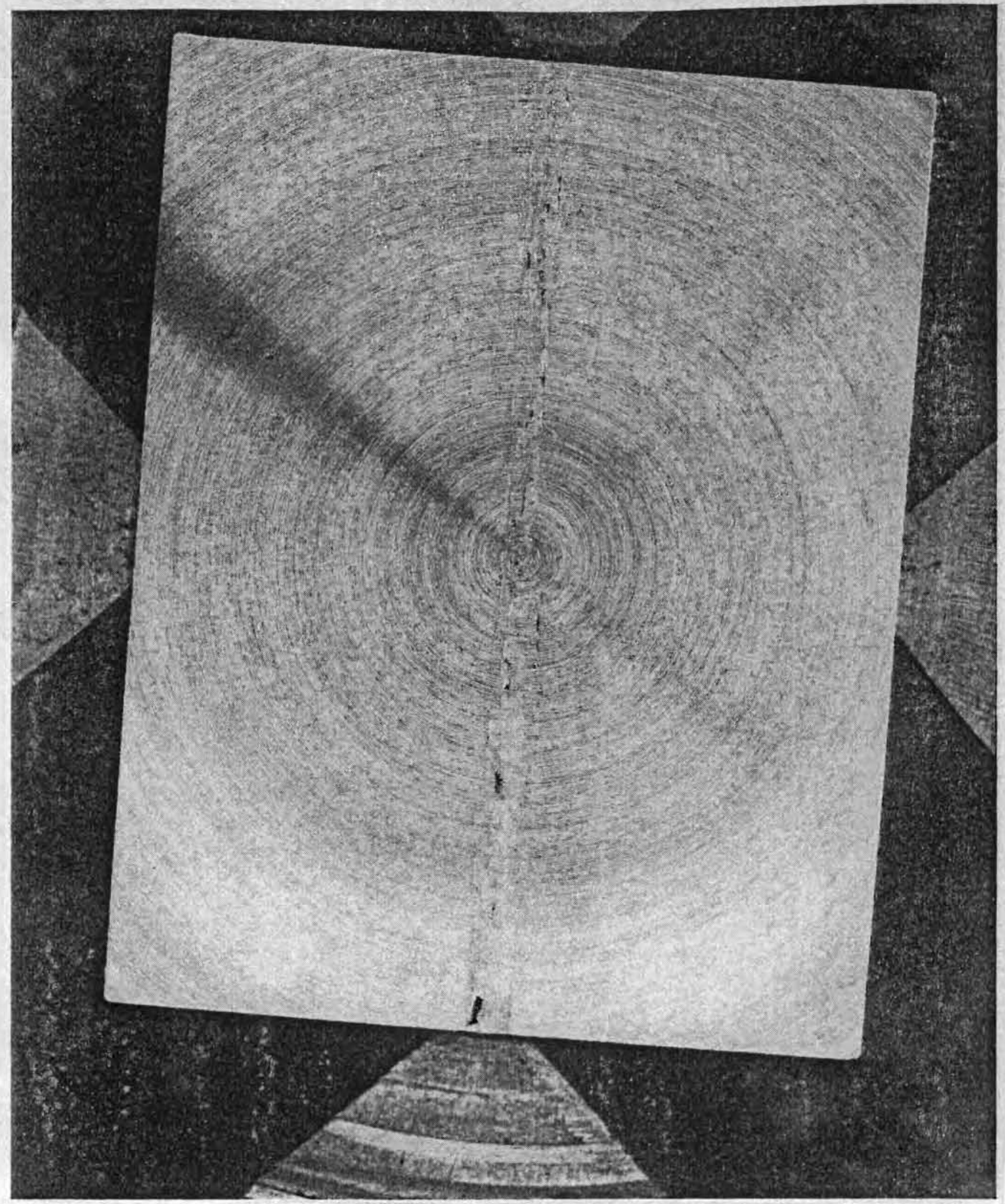

FIGURE 26. Core no. 169 with Extrusion Defect; Centerline Section View; Specimen Length 2 in. 
APPENDIX A

PNL REVIEW OF DRAFT SPECIFICATIONS

FOR AN AUTOMATED ULTRASONIC PRODUCTION

TESTING SYSTEM 
November 28, 1979

\section{Commanding Officer}

ARRADCOM

Dover, New Jersey 07801

Attention: John Stack, DRDAR-QAR-1, B]dg. 62

At the request of $\mathrm{Mr}$. Robert Sayer, PNL has reviewed the draft specifications for an automated ultrasonic inspection system for production testing of XM774 penetrators (letter from Mr. Ray Nelson, Rocky Flats, October 5, 1979). Comments on this draft specification are included, Comments are presented chronologically, with major sections and subsections referenced.

Reference

\section{Comment}

Is the Seller responsible for training of operating personnel

should really be under General Requirements

(add underline) The equipment shall include all components necessary for a complete operating unit ready to install by the buyer. Seller will provide a list of al1 pertininent components required to meet system specification.

(add sentence) The Seller will be furnished XM774 cores and ultrasonic standards for the performance testing. ARRADCOM will provide said material when requested by the Seller.

(re. fourth sentence) Perhaps one needs to be more specific here. Testing of each component to show mean-time-to-failure, etc. could be quite a task (e.g. instrument(s), mechanical drive, rotator, reject mechanism).

Who supervises installation and check out? Who determines final acceptance. 
Commander

ARRADCOM

November 28, 1979

$\underline{\text { Reference }}$

$(5.3)$
Comment

To what level of drafting requirements is needed? This has always been a difficult area. If drawings are to be to MIL SPEC, this could cost more than the equipment. If to commercial or manufacturer specifications, it could be alright. Does this mean assembly drawings or detail prints?

(second sentence) - requirements shall be described by sketch, connection details, if non-standard, layouts and instructions for installation.

(fourth sentence) Identification shall include manufacturer and part number or dimensions

Again detail or assembly?

Also, any modifications of original equipment.

Is system checking and quality test results in accordance with Seller's or Buyer's QA?

Original?

... automatic continuous mechanical rack feed

Need specific equipment, instrument, transducer, gates, alarm logic gates, etc.

Selectable?

re: identification - stamp/paint/?

Fail safe in the failure mode before and after test.

The tank and all associated components? The word "all" is unclear. Associated components should be specified. Stainless steel is not enough, must be passivated to prevent rusting.

refer to 7.1 comments. re: no corrosion?

Perhaps you should add or chemical reaction from $\underline{\mathrm{H}_{2} \mathrm{O} \text { additives. }}$ 
Commander

ARRADCOM

November 28, 1979

Reference

$(7.1 .4)$

$(7.1 .6)$

$(7.1 .7)$

$(7.3 .1)$

$(7.4 .1)$

$(7.4 .2)$

$(7.4 .4)$

\section{Comment}

Clarify, specify.

Serially feed? Does this mean end-to-end?

Seller will want to know how straight these 12 to 14 inch long cores are.

How round?

$\pm 5^{0}$ room ambient temperature.

The filter shall be capable of removing...

Weight of these core at 12 inches and 24 inches is needed.

This is determined by the required inspection rate, transducer beam width.

Rubber covered or ? Must have good surface wear properties and should not mark or scratch cores. If the core(s) is warped, will it be auto-rejected if it does not meet this 0.010 inch specification?

"butted" end-to-end, should be stated in $(7.1 .6)$.

Center line adjustment

resolution to 0.001 inch?

Backlash less than 0.002 inch and repeatability to 0.001 inch? if your backlash is 0.002 , you cannot show your repeatability to 0.001 inch. These are demanding requirements, perhaps too good.

Again, resolution to $1^{0}$ ? Repeatability to 0.5 ? You can't show your repeatability.

Production system may not need 5 inch capability. This is governed by system design and transducer selection. You do not specify repeatability here or adjustment tolerances. 
Reference

$(8.3 .6)$
Comment

Do not understand, manipulators have nothing to do with microprocessor control.

Means of switches? Why so outmoded?

$400 \mathrm{~Hz}$ ?

Accuracy, tolerances, for temperature limits?

Bandwidth response $500 \mathrm{KHz}$ to 10 or $15 \mathrm{MHz}$ is typical manufacturer. Certainly do not need 25 $\mathrm{MHz}$ when you test at $5 \mathrm{MHz}$ or less.

How measured?

$5 \mathrm{microsec}$. to $500 \mathrm{microsec}$.

0 microsec. to 500 microsec. calibrated?

This capability is exhibited with a few instruments. This is not important. This requirement would limit your Seller market for this job.

Shock or tuned?

Control of pulse length from what to what? Pulser damping controls cause changes in frequency of transmitted acoustic energy.

... from 0.200 to $15 \mathrm{MHz}$. This depends on broad-band or narrow band operation. Our experience with several (seven instruments) representative commercial instruments show the broad-band $-3 \mathrm{~dB}$ bandwidth ranging from 1.0/6.0 $\mathrm{MHz}$ to $50 \mathrm{KHz} / 65 \mathrm{MHz}$ is an example. The narrow band operation at $5 \mathrm{MHz}$ showed $-3 \mathrm{~dB}$ bandwidths of the receivers varied from $3.8 / 5.4 \mathrm{MHz}$ to 2.2/11.5 MHz (Sonic Mark II).

Total instrument gain of at least $100 \mathrm{~dB}$, adjustable in 1 or $2 \mathrm{~dB}$ steps. 
Commander

ARRADCOM

November 28, 1979

Reference

$(8.3 .7)$

\section{Comment}

Measured how? Some have $2.0 \mathrm{MHz}$ and would be fine.

Display a dynamic range of 50:1.

Display linearity within $3 \%$... Note, you say $1 \%$ in $(8.2 .2)$.

Take out. More than one instrument will be used for this sytem.

Is only one CRT required? Usually not the case.

Questionable data.

0 to 10 inches in steel.

$1 / 2$ to 20 inches in steel.

To date PNL Has used 2.25,5, and $10 \mathrm{MHz}$ (nominal) transducers for pulse-echo testing of DU cores. The Sonic Mark 11 was used to drive these transducers at the above frequencies using narrowband operation. The results of the transducer test showed that $5 \mathrm{MHz}$ operation would produce ultrasonic data with good resolution to small voids detection and good signal to noise ratio. Both spherically focused and line focused transducers were evaluated at the above frequencies. Using the $5 \mathrm{MHz}$ transducers the gain of the Mark II was 60 to $70 \mathrm{~dB}$, or half the system gain spec. at $120 \mathrm{~dB}$, (pulse-echo centerline void exam). Based upon this data and three years of testing I would suggest $5 \mathrm{MHz}$ narrow-band, spherically focused 0.5 inches diameter transducers be used for the centerline void exam. I would also use these same transducer specs. for the offset exam. and shear exam. The focal length will be determined by the manufacturer system design and will likely be 2-4 inches. 
Commander

ARRADCOM

November 28, 1979

Reference

General Comment -

(9.2)

$(9.4)$

\section{Comment}

The key to system performance, whereby I mean knowing where your system is truly operating can be determined by taking characterization measurements of the transducer and, of the transducer-instrument combination. In a letter report to Gravenstede, Sayer et al., data is presented showing the dramatic differences that can result when transducer selection is not controlled, (letter dated November 28, 1979). Refer to sections on transducer and instrument characterization.

Is this frequency nominal or is it the actual operating frequency of the transducer-instrument system. For example, that letter report to Gravenstede of November 28, shows a $5 \mathrm{MHz}$ nominal Aerotech transducer ( 0.5 diameter) driven with the Mark II pulser at $5 \mathrm{MHz}$ narrow-band operation (min. damping), giving a true peak operating frequency of inspection of 3.4 $\mathrm{MHz}$ when measured using a spectrum analyzer.

I suggest a test procedure outlining both transducer, and transducer-instrument characterization be furnished to the manufacturer in order to control test performance. The transducer characterization data described in this secton would be standard information from these characterization measurements.

Sincerely,

Chuck Morris

Nondestructive Testing Section

Batte 1 le Northwest Laboratories 
APPENDIX B

GLOSSARY OF TERMS USED TO EVALUATE

ULTRASONIC NDE EQUIPMENT 


\section{GLOSSARY OF TERMS USED TO EVALUATE ULTRASONIC NDE EQUIPMENT}

1. 1. Bandwidth (BW) $3 \mathrm{~dB}$ (BW) $6 \mathrm{~dB}$

2. Detector Dynamic Range

3. Damping Factor (Damp)

4. Duration (Dur)

5. Instrument Dynamic Range (ASTM 500)

6. Lower Frequency

$\left(f_{1}\right) 3 \mathrm{~dB}$

$\left(f_{2}\right) 6 \mathrm{~dB}$

7. Noise (ref. to input)

8. Peak Frequency (fp)

9. Peak Output (PO)

10. Peak-to-Peak Output
The difference between the upper frequency $\left(f_{2}\right)$ and the lower frequency $\left(f_{1}\right)$ where the response has decreased $3 \mathrm{~dB}$ or $6 \mathrm{~dB}$, i.e., $\left(f_{2}-f_{1}\right) 3 \mathrm{~dB}$ or $\left(f_{2}-f_{1}\right) 6 \mathrm{~dB}$.

The ratio in $d B$ of the maximum to minimum input signal that wi11 make. a distinguishable change in the detector output (detector plus filter at minimum filter position).

The number of half cycles of RF waveform divided by two. Only those half cycles that exceed $25 \%$ of the maximum peak-to-peak voltage will be counted.

The duration or length of the pulse in seconds measured from the $50 \%$ to $50 \%$ maximum output points.

The ratio in $d B$ of the maximum to minimum reflective areas that $c$ an be distinguished on the cathode ray tube at a constant gain setting.

The frequency less than the peak frequency where the response has decreased $3 \mathrm{~dB}$ or $6 \mathrm{~dB}$.

The noise voltage measured at the output of an amplifier at full gain with a $50 \mathrm{ohm}$ input termination using the tangential method divided by the gain of the amplifier.

Noise (ref. input $=\frac{\text { Noise RMS Output Voltage }}{\text { Gain }}$

The frequency at which the response is maximum.

The signal voltage measured from the baseline to the maximum voltage.

The signal voltage measured between the maximum positive and negative peak points.

1 Franklin, G. and Hatley, T., Don't Eyeball Noise, Electronic Design, Number 24, November, 1973 
11. Q

12. Receiver Gain

13. Rise Time (RT)

14. Signal-to-Noise Ratio

15. Upper Frequency

$\left(f_{2}\right) 3 \mathrm{~dB}$

$\left(f_{2}\right) 6 \mathrm{~dB}$
$Q$ is related to the sharpness of tuning and can be defined as:

$$
Q=\frac{\text { Peak Frequency }}{\text { Bandwidth }}
$$

where the $-6 \mathrm{~dB}$ bandwidth is used for determining the $Q$ of the pulse-echo transducer.

The ratio in $\mathrm{dB}$ of the output voltage to the input voltage: measured at full gain, at peak frequency and where the output is approximately $50 \%$ of the saturated output

$$
\text { Gain } d B=20 \log \frac{v \text { output }}{v \text { input }}
$$

The time required for the pulse to rise from $10 \%$ to $90 \%$ of its maximum output.

The ratio in $d B$ of the maximum (saturated) output to the output noise, i.e.,

$$
S / N=20 \log \frac{v \text { Sat (RMS) }}{v \text { Noise (RMS) }}
$$

or

$$
20 \log \frac{v \text { Sat (RMS) }}{v \text { Noise, RE. Input (RMS) } \times \text { Gain }}
$$

The frequency greater than the peak frequency where the response has decreased $3 \mathrm{~dB}$ or $6 \mathrm{~dB}$. 


\section{APPENDIX C}

TRANSDUCER CHARACTERIZATION TEST PROCEDURE 


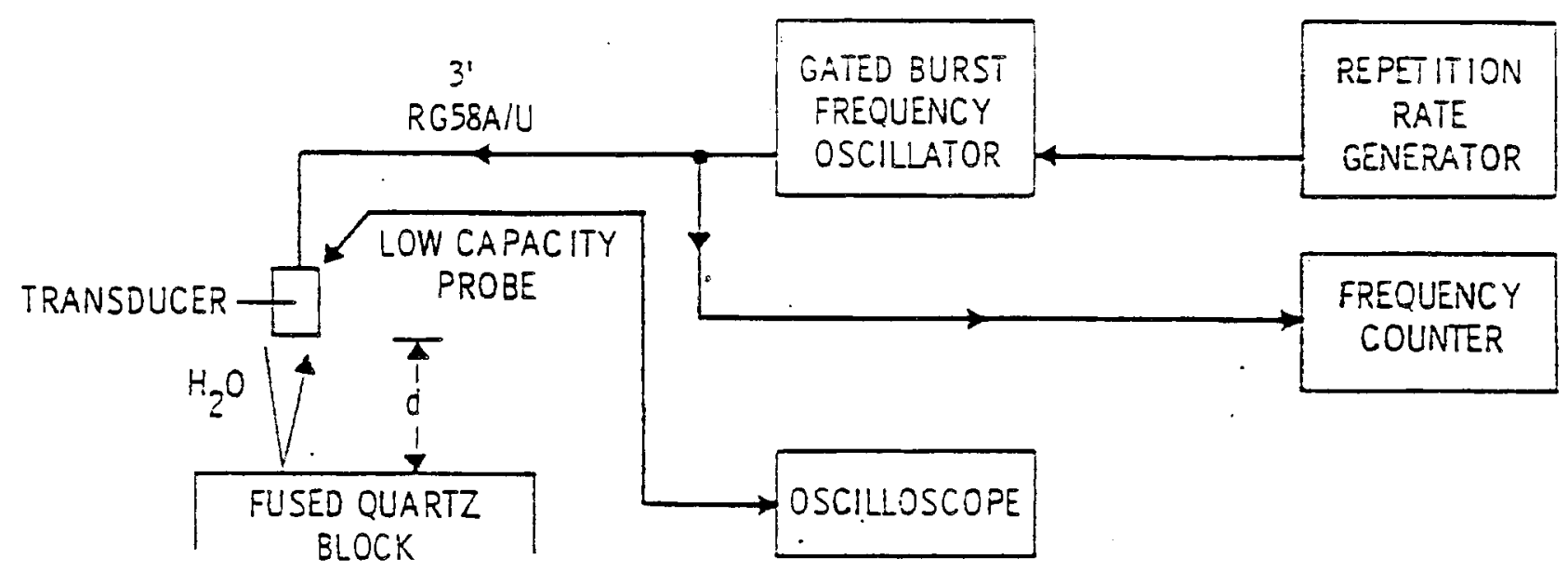

Equipment Recommended:

Gated Burst Frequency 0scillator

Repetition Rate Generator

Frequency Counter

Oscilloscope

Probe-Low Capacity Type
Tektronix FG504 Function Generator

Tektronix PG501 Pulse Generator

Tektronix DC503 Universal Counter

Tektronix 556 Oscilloscope WIAI

Tektronix X10 7 Pt. P-6008

1. Adjust the sound path, d, to: the transducer focal length; for flat transducers, set the last path length to the last peak in the far field, $D^{2} / 4$, where $D$ equals the transducer diameter.

2. Normalize the transducer to the surface of the fused quartz block in both orthogonal axis by maximizing the reflected pulse at the transducer peak frequency.

3. Plot the amplitude of the reflected pulse versus frequency, keeping the excitation voltage across the transducer constant each time the frequency is counter. Note: The oscillator must be switched to continuous wave for a frequency measurement. Disconnect the transducer from the circuit during continuous wave operation to avoid damage.

4. From the amplitude versus frequency plot, the following parameters can be obtained:

A. peak frequency

B. upper and lower $6 \mathrm{~dB}$ points

C. band width

D. Q

E. Insertion loss at peak frequency

Note: See glossary of terms for clarification and definition of terms. 

APPENDIX D

TRANSDUCER IMPEDANCE PLOTS

AND TONE BURST SPECTRUM DATA 


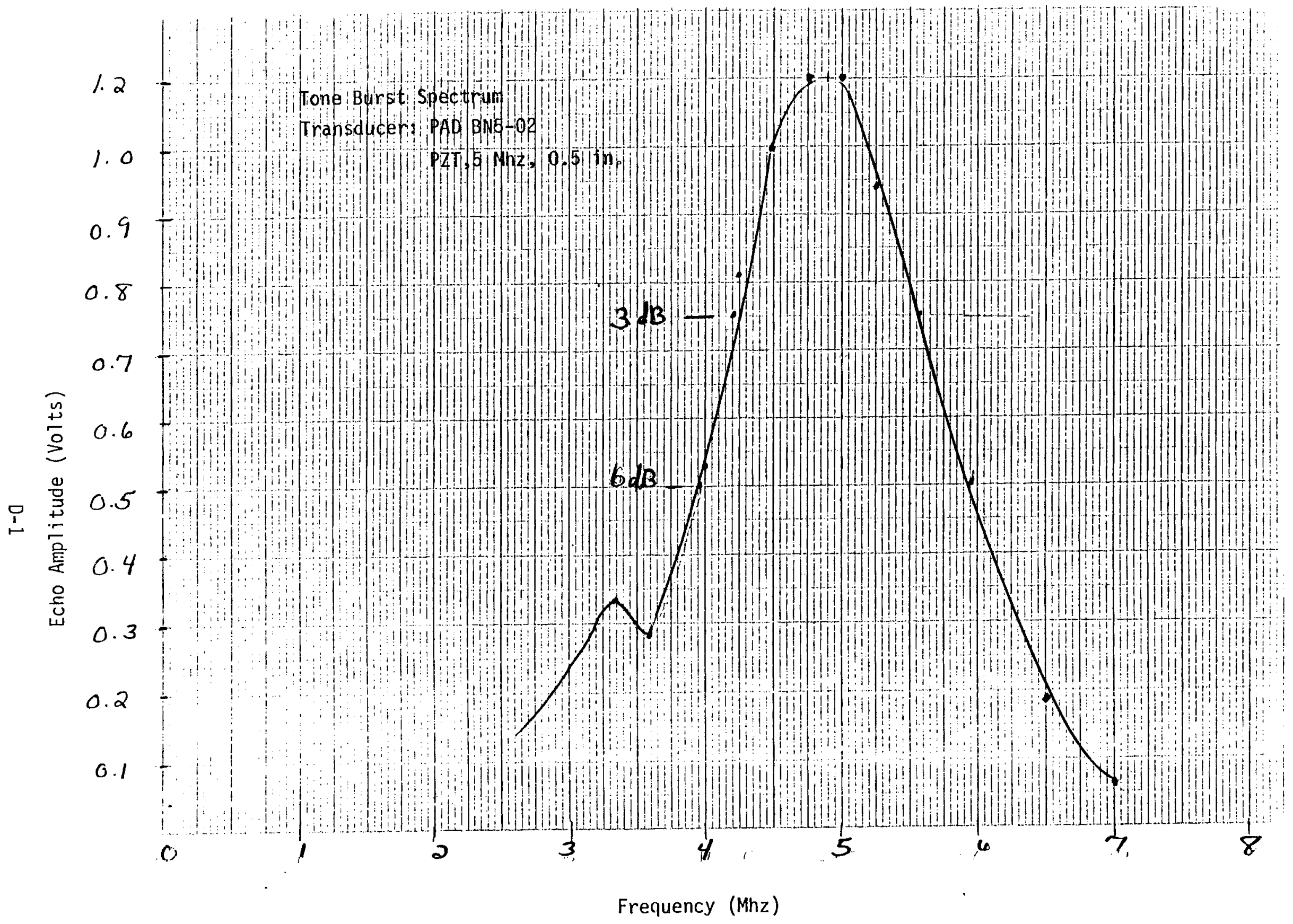


Impedance P1ot: PAD BlN5-02, PZT, $5 \mathrm{Mhz}, 0.5$ in.

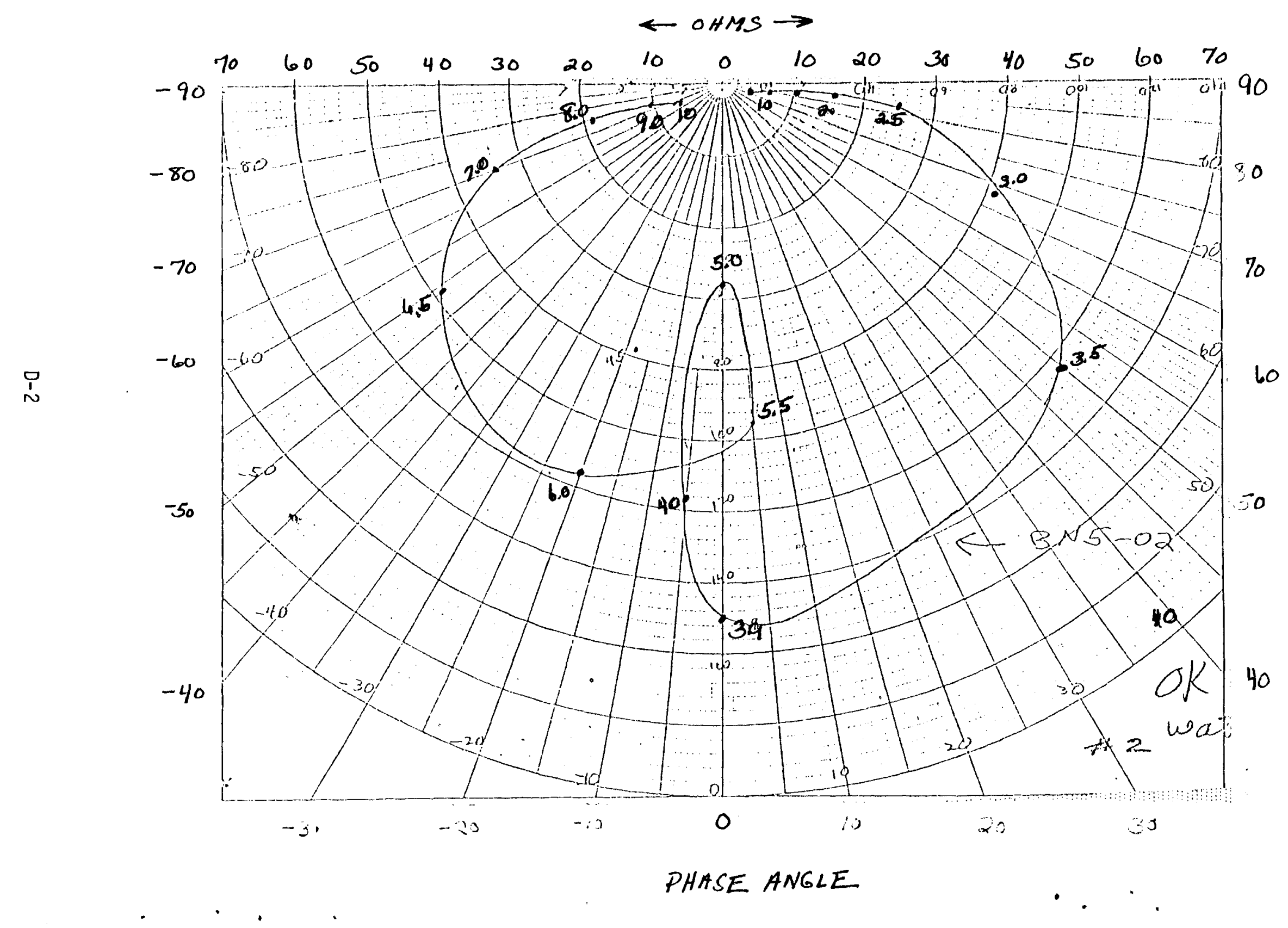


Impedance Plot: Harrisonic, R571 Pblet, 131006T, $10 \mathrm{Mhz}, 0.375$ in.

$\stackrel{p}{+}$

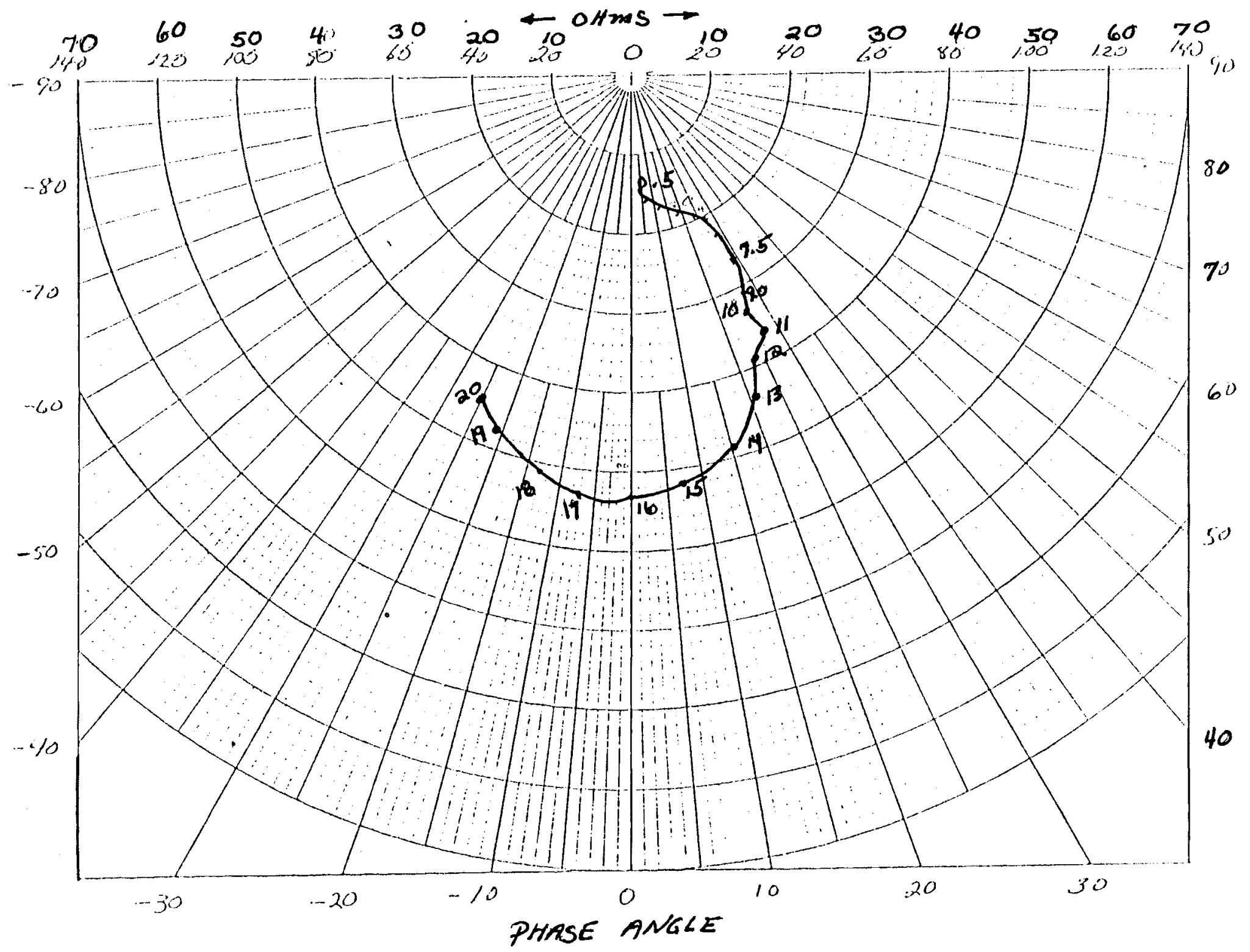




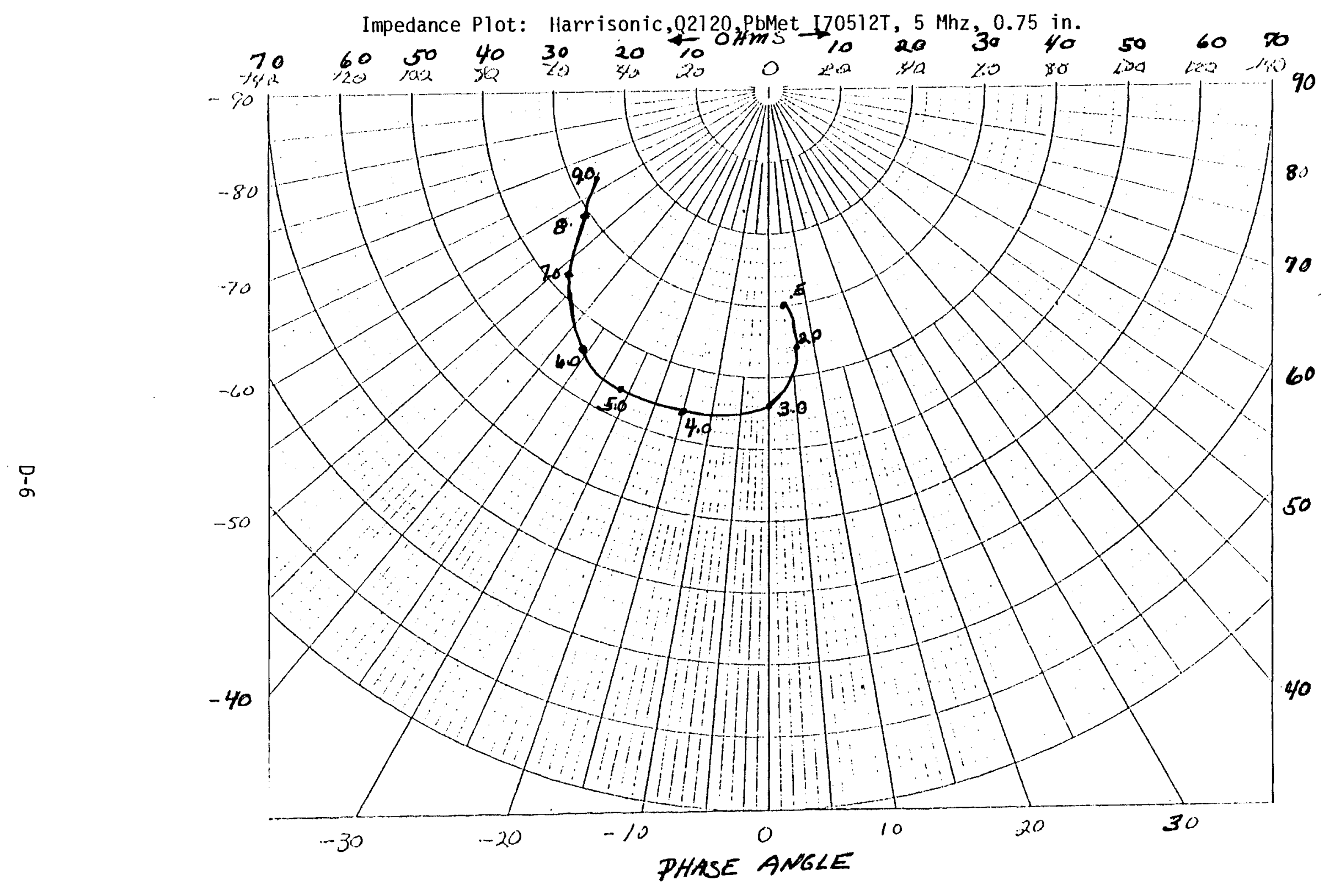


APPENDIX E

TEST PROCEDURE FOR ULTRASONIC EQUIPMENT

CHARACTERIZATION 
The following test procedure is being used to evaluate currently available ultrasonic equipment. Each unit is tested at the point indicated in the block diagram below. Also listed below is the equipment used in the evaluation procedure.

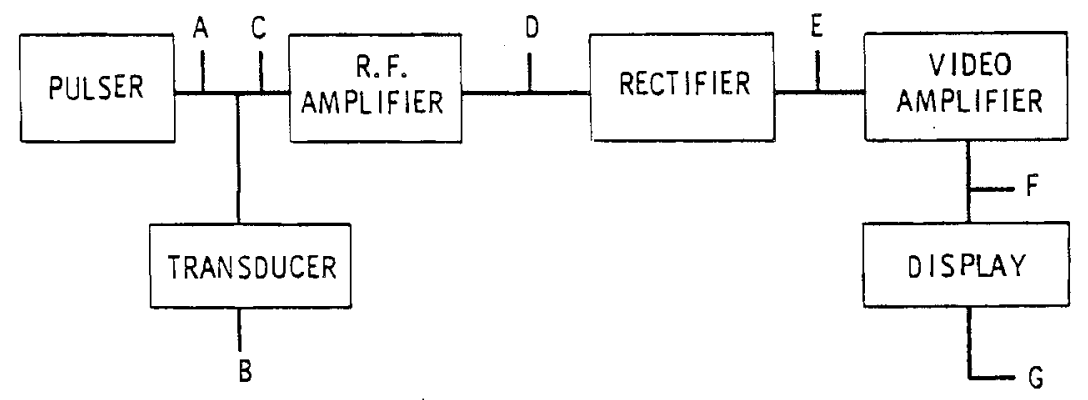

Equipment List

1. Tektronix 547 oscilloscope with $1 A 1$ plug-in unit or equivalent.

2. Hewlett Packard spectrum analyzer $8553 \mathrm{~L}$ or equivalent.

3. Sync buffer - Data Pulser SD-100A pulse generator.

4. Stepless gate Panametric peak detector 5052 GPO-2.

5. Test transducer: $5.0 \mathrm{MHz}$; untuned $\mathrm{Pb}$ Met.; $12.7 \mathrm{~mm}(1 / 2$ inch) diameter; flat $100 \mathrm{~mm}$ ( 4 inch) focal length.

6. Broad Band Transducer; $25.0 \mathrm{MHz}$, untuned, $12.7 \mathrm{~mm}(1 / 2$ inch) diameter; flat.

7. Coaxial Cable: RG $58 \mathrm{~A} / \mathrm{U}, 1.85 \mathrm{~m}(6 \mathrm{ft})$ length.

8. Quartz block.

9. Low capacitance probe; 7 pf $-10 x$ or $100 x$.

10. 50 ohm Load; Tektronix 110-0049-01 or equivalent.

I. Test Point A - Pulser Output

1. The output of the pulser is characterized by measuring:

* Spectral content of pulse

* Pulse voltage

* Observing $r f$ waveform to determine

a. rise time

b. duration or length 
2. The effects of damping control or pulse length control settings on pulser output are observed at minimum and maximum settings of each of these controls.

3. The output of the pulser as characterized above is checked at $5.0 \mathrm{MHz}$ and/or broadboard:

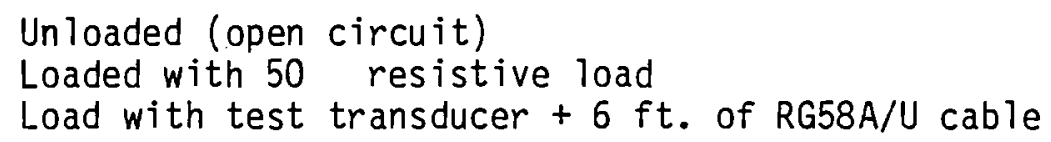

4. A block diagram of the test circuit is given below:

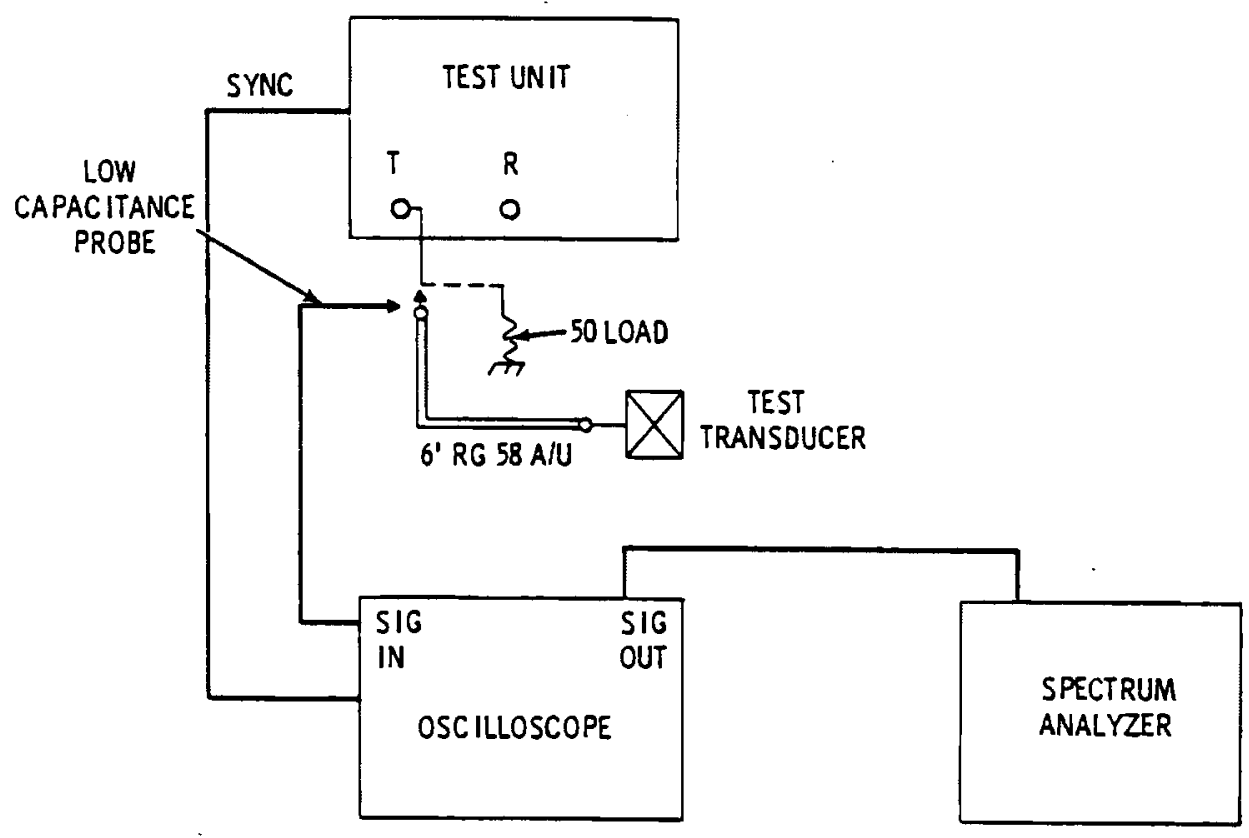

II Test Point B - Transmitted acoustic wave from $5.0 \mathrm{MHz}$ Test Transducer

1. The transmitted acoustic wave is characterized by measuring or observing:

Spectral content, band width and center frequency of transmitted wave

RF waveform of transmitted wave

2. The measurements are made by pulsing test transducer into broadband $25 \mathrm{MHz}, 1 / 2$ inch diameter lithium sulfate transducer.

3. Measurements are made at all control settings measured at Point $A$. 
4. The test equipment and block diagram of test circuit are shown below:

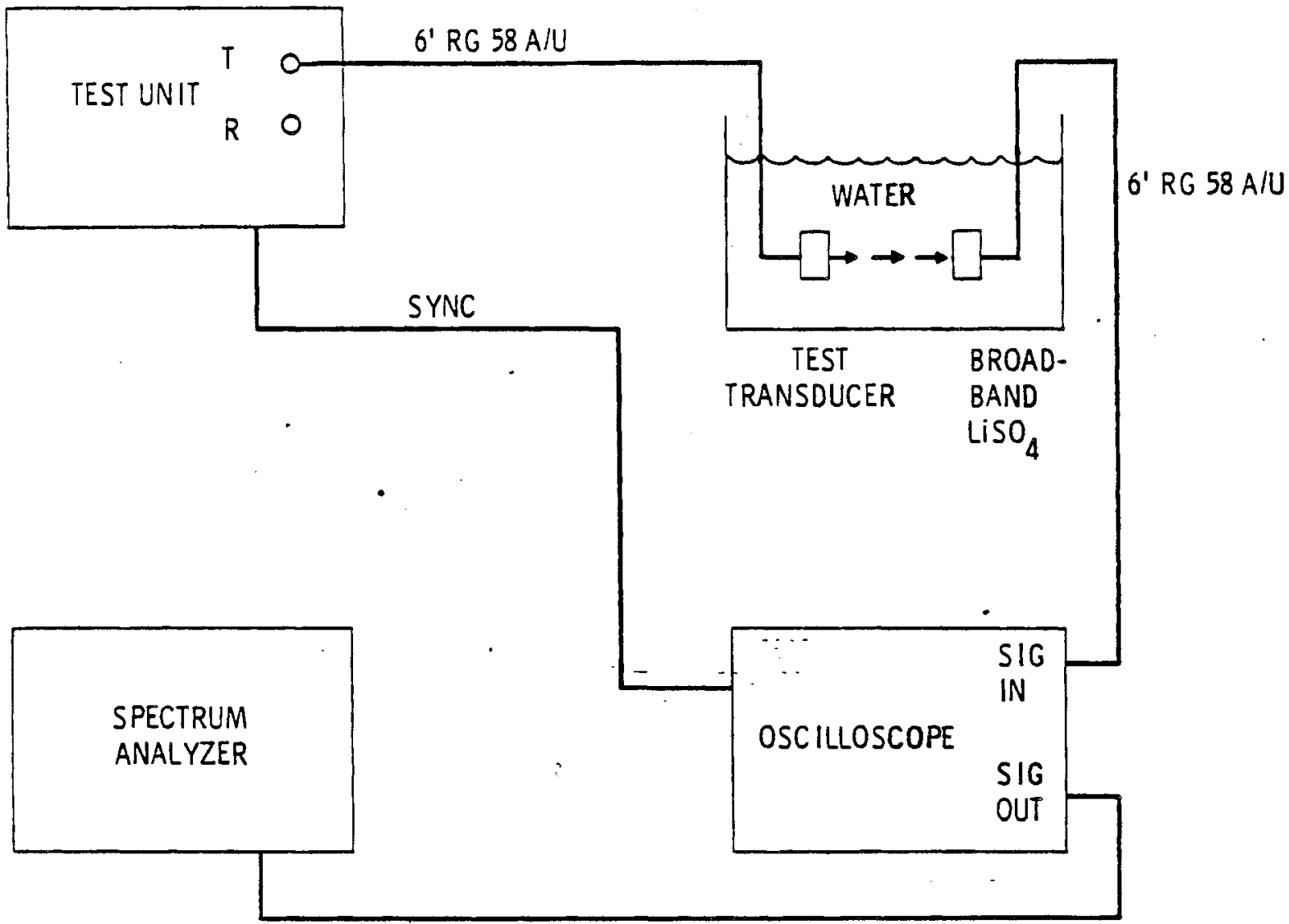

III. Test Point C - Reflected Acoustic Signal

1. The reflected acoustic signal produced by pulsing test transducer used at "A" onto a flat surface (i.e., quartz block) is characterized by measuring and observing:

Spectral content, band width and peak frequency of signal RF waveform

a. wave shape

b. distortion of waveform transmitted acoustic signal

2. The received signal is characterized at all control settings used for measurement at Point $A$ with test transducer load.

3. The test equipment and a block diagram of test circuit are sketched on the following page: 


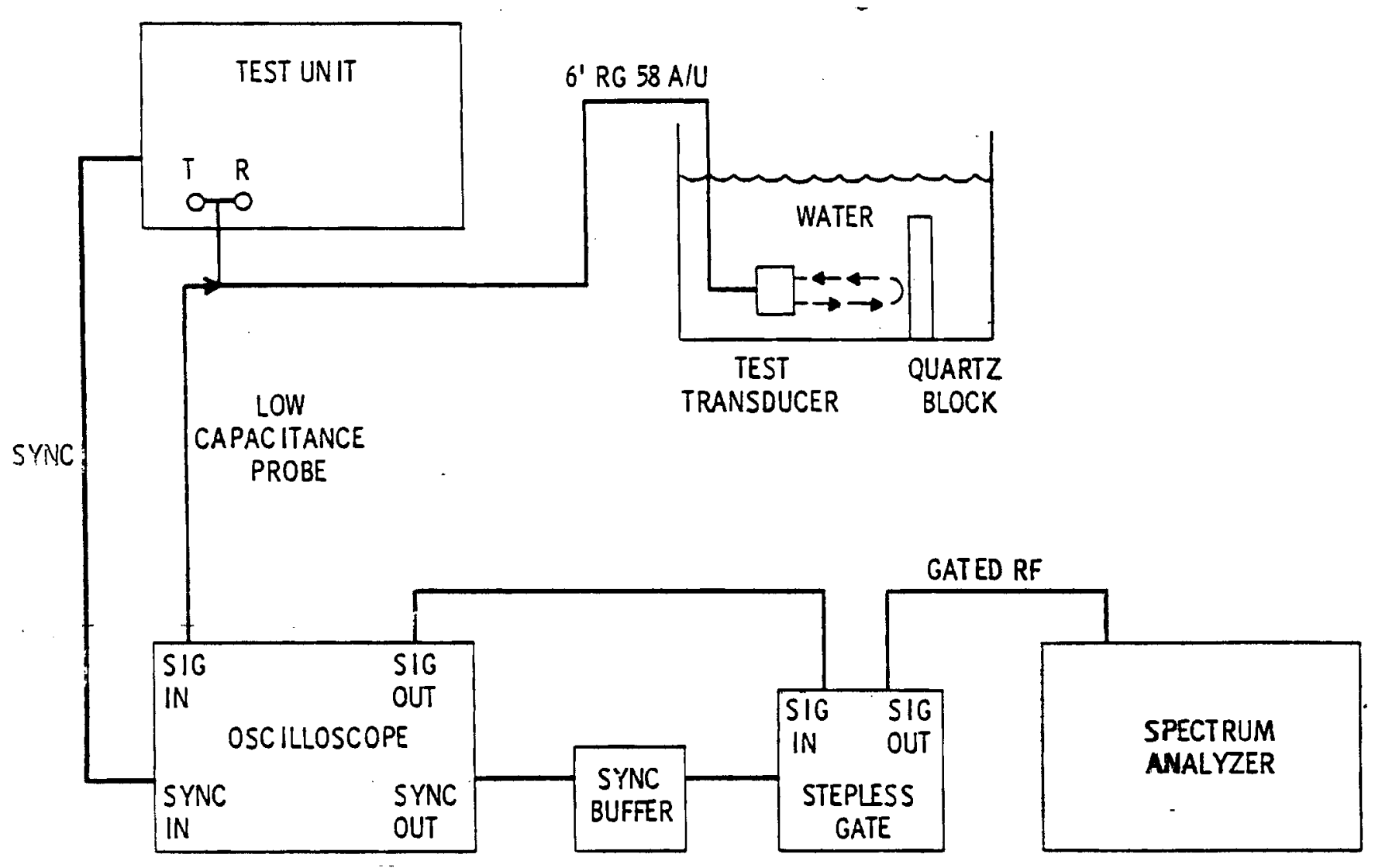

IV. Test Point D - Amplifier and Amplified Acoustic Signal

1. Amplified Acoustic Signal

a. Test Point $D$ is used to characterize signal amplification of the test unit.

b. The amplified acoustic signal from Point $C$ is characterized by measuring and observing:

Spectral content and band width

RF waveform

a. distortion of received acoustic signals

b. signal frequency shift

c. saturation and recovery of amplifier 
c. The test equipment and block diagram used for characterizing amplified acoustic signal are shown below:

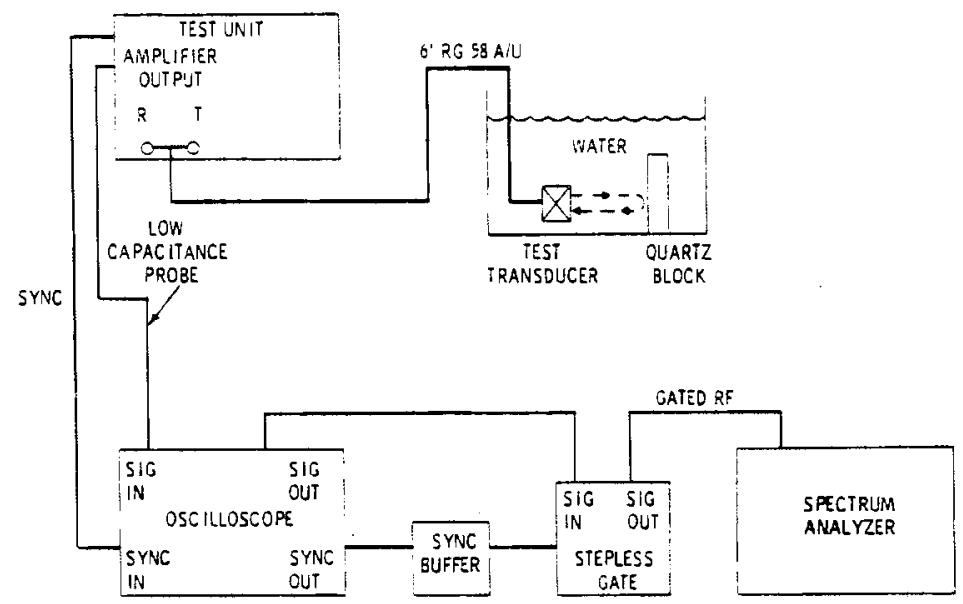

2. Amplifier Measurements and Determinations

a. Peak Frequency - The frequency at which the response is maximum.

b. Band width - The difference between the Upper Frequency $\left(f_{2}\right)$ and the Lower Frequency $\left(f_{1}\right)$ where the response has decreased $3 \mathrm{~dB}$ or $6 \mathrm{~dB}$.

c. Signal-to-Noise - The ratio in $d B$ of the maximum (saturated) output to the noise output, i.e.,

$$
\begin{aligned}
& S / N=20 \log \frac{V(\max . \text { output) }}{V \text { noise (ref. input RMS) } \times \text { gain }} \\
& \text { or } \\
& S / N=20 \log \frac{V \text { (max. output) }}{V \text { noise RMS }}
\end{aligned}
$$

d. Noise (Ref. to input) - The noise voltage measured at the output of an amplifier, at full gain with a $50 \mathrm{ohm}$ input termination, using the tangentiai method ${ }^{1}$ divided by the gain of the amplifier.

e. Receiver Gain - the ratio in $d B$ of the maximum unsaturated voltage to the input voltage; measured at full gain and at peak frequency.

$$
\text { Gain } d B=\frac{V \text { output }}{V \text { input }}
$$

IFrankTin, G. and Hatley, T., Don't Eyeball Noise, Electronic Design, Number 24, November, 1973. 
V. Test Point $E$ and/or F - Detected and/or Video Drive or Amplified Acoustic Signal

1. At test $E / F$ depending upon accessibility of test unit the detected or video drive signal of the amplified acoustic wave is characterized by measuring and observing:

Rectified signal

a. classify detector type - halfwave or full wave

b. check for distortion of rectified signal over rf input

c. check dynamic range

d. linearity

2. A list of equipment and block diagram of test circuit are shown below:

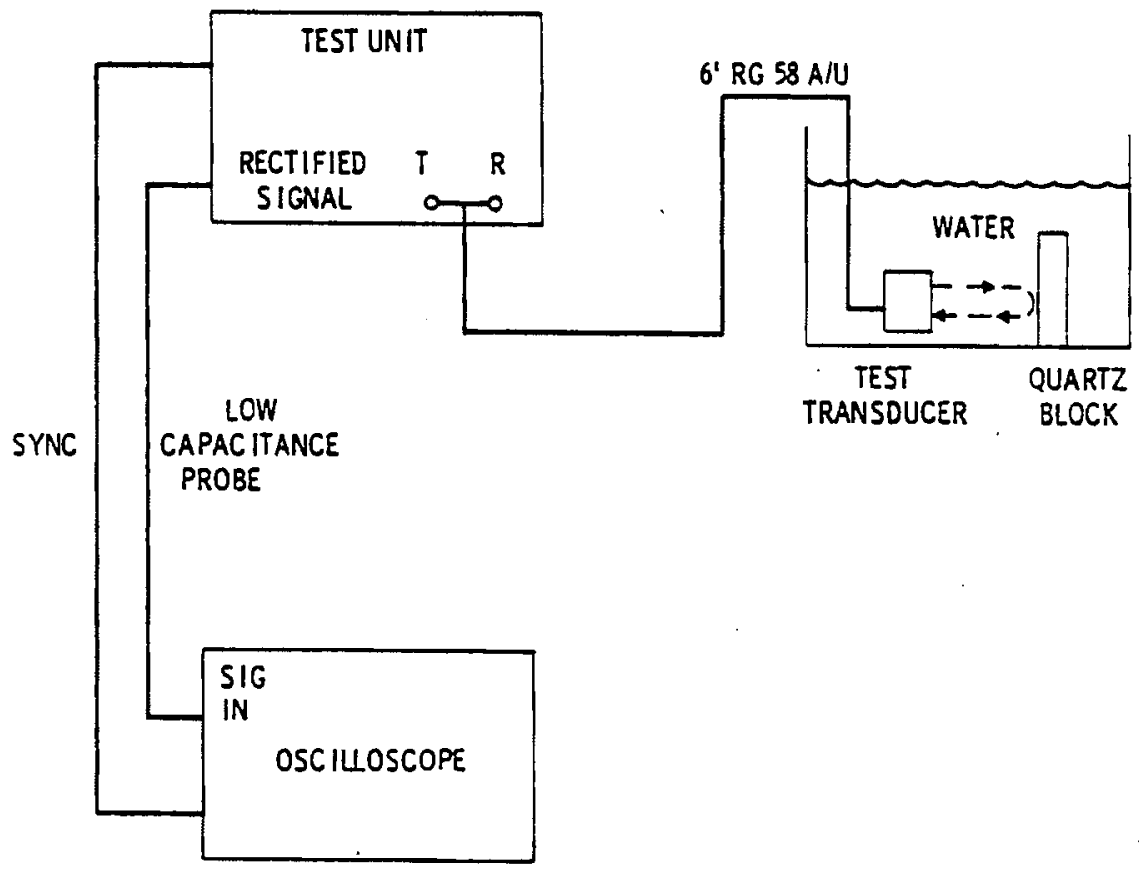

VI. Test Point G - Observed Signal on Test Unit CRT

1. The display of the test unit is characterized by observing

Distortion of signal from the observed at Point $F$ or $E$. Determine if "reject" or clipping is present. 


\section{DISTRIBUTION}

No. of

Copies

\section{OFFSITE}

A. A. Churm

DOE Patent Division 9800 South Cass Ave. Argonne, IL 60439

Commanding Officer Department of the Army U.S. Army Armament Research and Development Conmand (AARADCOM) Dover, NJ 07801

C. Knudsen, DR-DAR-QAR-M Department of the Army U.S. Army Armament Research and Development Command (AARADCOM)

Dover, NJ 07801

F. Clark, DR-DAR-QAR-1 Department of the Army U.S. Army Armament Research and Development Command (AARADCOM)

Dover, NJ 07801

J. Cappetta, DR-DAR-QAR-1 Department of the Army

U.S. Army Armament Research and Development Command (AARADCOM)

Dover, NJ 07801

J. Stack, DR-DAR-QAR-1 Department of the Army U.S. Army Armament Research and Development Command (AARADCOM) Dover, NJ 07801
No. of

Copies

M. Wi enberg, DR-DAR-QAR-1

Department of the Army

U.S. Army Armament

Research and Development

Cormm and (AARADCOM)

Dover, NJ 07801

D. HuTbert, DR-DAR-SCW-P

Department of the Army

U.S. Army Armament

Research and Development

Command (AARADCOM)

Dover, NJ 07801

3 B. Sayer, DR-DAR-LCU-CT

Department of the Army

U.S. Army Armament

Research and Development Command (AARADCOM)

Dover, NJ 07801

3 N. Gravenstede, DR-DAR-QAR-M

Department of the Army

U.S. Army Armament

Research and Development

Command (AARADCOM)

Dover, NJ 07801

R. Darcy, DR-DAR-QAR-M

Department of the Army

U.S. Army Armament

Research and Development

Comm and (AARADCOM)

Dover, NJ 07801

R. Neison

Rockwe 17 Internationa 1

Rocky Flats Plant

P.0. Box 464

Golden, CO 80401 
No. of

Copies

M. Michael

Rockwell International

Rocky Flats Plant

P.0. Box 464

Golden, CO 80401

2 A. Gilman

Nuclear Metals, Inc. 2229 Main St.

Concord, MA 41131

D. Purinton

Nuclear Metals, Inc.

2229 Main St.

Concord, MA 41131

A. Geary

Nuc lear Metals, Inc.

2229 Main St.

Concord, MA 41131

E. Tenerini

Nuclear Metals, Inc.

2229 Main St.

Concord, MA 41131

27 DOE Technical Information Center

D. Johnson

Reluxtrol Company

333 Victory Ave.

South San Francisco, CA 94080

4 L. Levy

National Lead Co. of Ohio

Feed Materials Production Center Box 39158

Cincinnati, $\mathrm{OH} \quad 45239$

2 J. Conboy

$\mathrm{NL}$ Industries

1130 Central Ave.

Albany, NY 12205
No. of

Copies

2 H. Scranton

$\mathrm{NL}$ Industries

1130 Central Ave.

Albany, NY 12205

A. Duncan

Chamberlain Manufacturing Corp.

East 4th and Esther St.

Water 100 , IA 50705

\section{ONSITE}

DOE Richland Operations Office

H. E. Ransom

Pacific Northwest Laboratory

B. Kemper

K. Sump

S. Foreman (3)

C. Morris (3)

Technical Information (5)

Publishing Coordination (2) 